\title{
Estándares para la medición de la gestión del desarrollo local
}

\author{
Standards for Evaluating the Management of Local Development
}

\author{
Álvaro Sáenz Andrade?
}

\section{Resumo}

Este documento trata de dar un paso para contar con instrumentos que permitan la evaluación periódica de la gestión de los procesos de desarrollo en toda su dimensión, cuando las iniciativas del desarrollo local no cuentan aun con sistemas e indicadores que faciliten analizar y comparar el nivel alcanzado, constatar falencias y retroalimentar la gestión.

Palavras-chave : Instrumentos de evaluación; desarrollo local; gestión pública

\section{Abstract}

This paper deals with instruments that allow a periodic evaluation of the management of development processes in all their dimensions, when local development initiatives do not have system of indicators that make easy the analysis and the comparison of the obtained level, the identification of bankruptcy, and management's feedback.

Key-words: Evaluation instruments; local development; public management

\section{Introdução}

En las últimas décadas se han puesto en marcha numerosas experiencias de gestión orientadas a lograr procesos de desarrollo y a aproximar los gobiernos locales con los ciudadanos. Estas experiencias se han implementado utilizando variadas herramientas y guías metodológicas, sobre todo con el propósito de hacer planificación estratégica participativa, sin embargo han descuidado otros ámbitos necesarios para la administración del desarrollo como son: la gestión de planes, el desarrollo de capacidades institucionales y la articulación entre lo local y lo nacional.

Este documento trata de dar un paso para contar con instrumentos que permitan la evaluación periódica de la gestión de los procesos de desarrollo en toda su dimensión; cuando las iniciativas del desarrollo local no cuentan aun con sistemas e indicadores que faciliten analizar y comparar el nivel alcanzado, constatar falencias y retroalimentar la gestión.

Su enfoque está en la gestión y, por ende, se concentra en evaluar la capacidad de conducir los procesos, más que en los propios resultados del desarrollo. El eje y aporte de esta propuesta es verificar si se está haciendo una

Este texto está basado en el documento elaborado por el autor para la Oficina de Planificación Nacional -ODEPLAN, la Asociación de Municipalidades del Ecuador AME, el Consejo Nacional de Mujeres -CONAMU, el Ministerio del Ambiente y el Instituto Nacional de Estadística y Censos -INEC, con la asistencia del Fondo de Población de las Naciones Unidas -UNFPA. Se trata de un trabajo de construcción interinstitucional. Ha sido presentado en el Encuentro Latinoamericano de Desarrollo Local, Cuenca-Ecuador, Septiembre 2005.

Mestre em Socilogia pela Consejo Latinoamericano de Ciencias Sociales - Pontificia Universidad Católica del Ecuador. Professor da Universidad Andina Simón Bolivar. Endereço: Calle R. Audiencia No. 73 - Sucre - Bolivia. E-mail: asaenz@andinanet.net.

Artigo recebido em agosto/2006 e aceito para publicação em outubro/2006. 
gestión con capacidad, calidad y sostenible en el tiempo. Para ello se analizan las condiciones de sostenibilidad de la gestión del desarrollo local que son críticas, como la construcción de un tejido social de apoyo a los procesos del desarrollo, la apropiación por parte del municipio y demás actores del rol de gobierno local, la existencia de planes locales en ejecución, el incremento de capacidades institucionales y la articulación a los procesos y sistemas regionales y nacionales.

El sistema desarrollado pretende ser una herramienta estratégica de reflexión y fortalecimiento de los procesos de desarrollo local, además de su valor como instrumento de medición que evidencie donde comienza un proceso y sus avances en el tiempo. Su uso principal es proveer de un estado de situación del proceso de desarrollo local, como base para identificar estrategias de mejoramiento de las capacidades de gestión de dicho proceso.

Esta herramienta ha recogido la experiencia de varias instituciones y personas vinculadas con el desarrollo local y ha sido probada en varios municipios ecuatorianos y de otros países. Es un instrumento dirigido a autoridades, actores locales y entidades de apoyo, para que puedan evaluar si sus procesos tienen capacidad y continuidad.

\section{1. Áreas de evaluación del proceso de desarrollo local}

Las reflexiones sobre el estado actual del desarrollo local plantean la necesidad de conjugar una serie de componentes para lograr procesos sostenidos de desarrollo. Este conjunto de condiciones de sostenibilidad generalmente es descuidado, privilegiando a alguna de ellas, sin el concurso de las demás. El caso más claro ha sido que en las últimas décadas los expertos en desarrollo se han concentrado en la planificación estratégica local, descuidando la gestión de gobierno, la creación de capacidades institucionales e incluso la construcción de capital social. Por ello, para medir el conjunto de capacidades logradas en los procesos locales se proponen las siguientes áreas de evaluación:

Figura 1: Áreas de Evaluación propuestas 


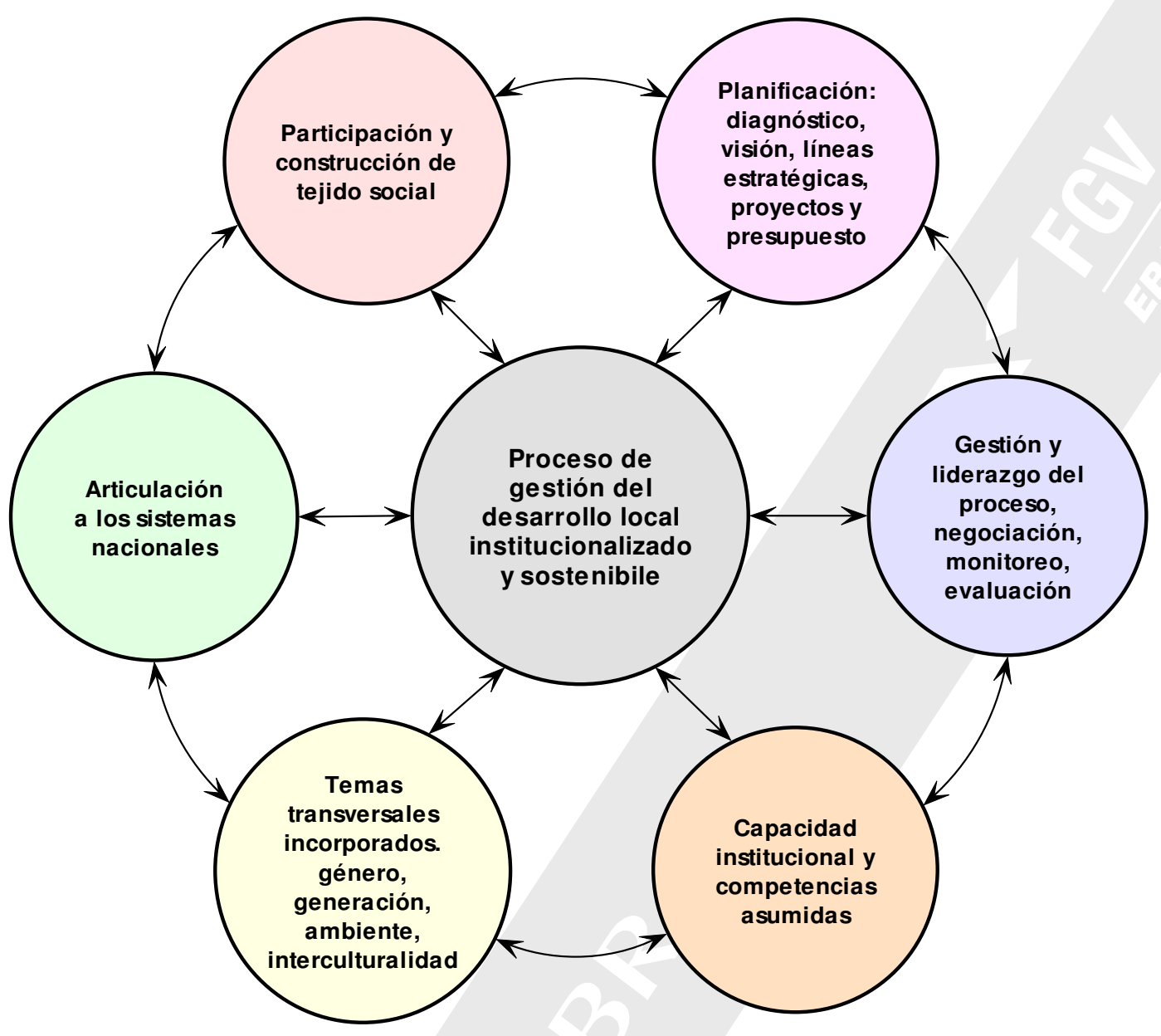

Fuente: Elaboración própia

El producto esperado de la evaluación (presentado en el círculo central) es medir si el proceso de desarrollo local ha logrado institucionalizar sus capacidades y si se encuentra activo y sostenido. En definitiva, se pone el énfasis en la creación de capital humano (capacidades) y en la consolidación de los espacios de desarrollo del capital social (institucionalidad) como base de procesos que aporten realmente al progreso local y sean sostenibles en el tiempo.

Para lograr la sostenibilidad se requiere la confluencia de un conjunto de condiciones articuladas entre sí, como son: la construcción de un tejido social, la planificación y gestión de un plan local, la construcción de capacidades institucionales, la asunción de competencias descentralizadas, la respuesta dada a temas transversales centrales y la articulación al desarrollo nacional y sus sistemas.

\section{Participación y construcción de tejido social}

Una condición básica de sostenibilidad es la participación activa y el empoderamiento de ciudadanos y ciudadanas, desde la base, en los procesos, actividades, recursos, proposiciones y decisiones del desarrollo. Esta participación se agrega en procesos de concertación entre actores diversos hasta lograr construir un tejido social. Esta construcción permite que el proceso de desarrollo local cuente con el sostenimiento social necesario a la vez que es la oportunidad de generar una forma de democracia activa.

El tejido social está compuesto por la relación activa y concertada entre todas las organizaciones e instituciones que hacen la vida local. Estas incluyen a las organizaciones sociales, populares, productivas, grupos de mujeres, jóvenes, niños y niñas, iglesias, ONGs y el sector público que tiene incidencia local. Se habla de masa crítica acogiendo el concepto referido al logro de un grupo lo suficientemente grande de actores que se suman a un proceso, de tal manera que se vuelve irreversible. Esta construcción requiere del manejo de herramientas técnicas de mapeo social, capacidad de convocatoria, acciones de contraloría social, capacitación de actores sociales, planificación participativa y creación de institucionalidad que facilite la participación. 


\section{Planificación}

La planificación estratégica participativa es un componente necesario para que exista un proceso de desarrollo más allá de las acciones puntuales y períodos electorales. A la vez permite una mirada a la compleja realidad cantonal con el aporte de problemas y propuestas de solución provenientes de la diversidad de actores locales.

Esta planificación se está practicando desde hace más de 10 años en el país y se cuenta con amplia experiencia sobre ella. Sin embargo tiene el reto de lograr simplificarse y desembocar en la construcción de presupuestos institucionales adecuados al plan. Planificar implica el desarrollo de una visión de futuro compartida, la apuesta por algunas de las líneas estratégicas de acción, la identificación y diseño de proyectos adecuados y la asignación de inversión para el desarrollo del plan.

Este último aspecto, la asignación de recursos de inversión para viabilizar el plan, ha sido tradicionalmente descuidado en la planificación. Por el contrario, este sistema de evaluación privilegia la presupuestación como una parte sustancial del proceso de planificación, que debe reflejar una asignación y manejo de recursos en función directa a las decisiones del plan y sus proyectos.

\section{Gestión y liderazgo del plan}

La gestión de procesos de desarrollo es la generación de capacidades locales para lograr una mejor calidad de vida y no solamente un ordenamiento de la gestión de obras. Una de las mayores debilidades de los procesos de desarrollo local se asienta en la falta de capacidad e las ineficiencias de gestión del plan, donde de puede agrupar todo lo referente a ejecución y cumplimiento de actividades, toma de decisiones en la acción, ejecución presupuestaria y participación social en la gestión.

Se considera que este concepto es más amplio que el de administración o implementación de un plan. Consiste en un proceso dinámico que involucra a varios actores locales, y los compromete a una actitud positiva que permita cambiar la situación. La gestión incluye el manejo participativo de programación, inversión efectiva y manejo de los recursos en función del plan, monitoreo de procesos, evaluación, negociación, manejo de conflictos y rendición de cuentas.

\section{Capacidad institucional}

La capacidad institucional es el conjunto de organización, normatividad, tecnología y capacidades técnicas y humanas de una institución. La generación de capacidad institucional, sobre todo a nivel de gobiernos locales, es una condición básica para dinamizar el desarrollo y el sustento para asumir nuevas funciones a nivel local. Incluye capacidades técnicas de planificación y gestión y de conocimientos especializados en ámbitos de ordenamiento territorial, desarrollo social, económico y ambiental, y prestación de diversos tipos de servicios. Lograrlo implica el manejo de enfoques conceptuales y herramientas en diversos ámbitos como el jurídico, de fortalecimiento institucional, diseño y gestión de procesos, potenciación de recursos humanos, manejo de sistemas de información y planeación institucional.

Dentro de las capacidades institucionales está la de generar ingresos por fuera del presupuesto del Estado. Incluye la capacidad de recaudación y la existencia de sistemas para ello. Así mismo se puede tomar como parte de la capacidad institucional, la asunción de nuevas competencias por parte de los gobiernos locales, dentro del proceso de descentralización en que está inmerso el Ecuador.

También en las capacidades se enmarcan las nuevas funciones asumidas por los gobiernos locales mediante las demandas de descentralización.

\section{Temas transversales incorporados - enfoques}

El manejo de ejes transversales de comportamiento que actualmente están en vigencia como género, generación, interculturalidad y ambiente, es una condición necesaria de la gestión y muestra la capacidad de respuesta de un proceso a los grupos humanos y sus condiciones necesarias. Estos ejes requieren ser evaluados mediante la identificación de logros en participación, relaciones equitativas y reducción de las brechas y reconocimiento de la diversidad. Se debe evidenciar y valorar los intereses de mujeres y hombres, jóvenes, niños y niñas, terce- 
ra edad y culturas diversas; incorporando a estos enfoques la preocupación por el ambiente y la sostenibilidad local, en la definición de los diversos planes, proyectos, propuestas y realizaciones.

Esta incorporación enriquece a los gobiernos locales tanto con la presencia de un nuevo modo de enfrentar las relaciones y recursos del desarrollo y oportunidades, como con las metodologías de trabajo actualizadas que se incorporan a través de estos temas. En la matriz de indicadores, la medición de estos temas está articulada a las demás condiciones de sostenibilidad por el hecho de que son transversales. Así, por ejemplo, en los indicadores de planificación se observará si los temas de género, interculturalidad y ambiente se encuentran debidamente incorporados.

Dado el carácter transversal de estos temas, no se ha abierto una matriz específica de indicadores, sino que estos han sido incorporados a cada una de las demás áreas de evaluación y son procesados luego de manera particular.

\section{Articulación a los sistemas nacionales}

Finalmente el desarrollo local no puede ser tal, si no se reconoce que la descentralización tiene una dimensión de articulación nacional que complementa lo local. Si bien las parroquias, los cantones y las provincias y sus gobiernos son un espacio privilegiado de desarrollo, solamente prosperan cuando están articulados al espacio nacional. Lo local debe incorporarse a la reflexión sobre políticas públicas, nacionales y locales, para ser parte de una visión común de país.

Esto implica la articulación entre los gobiernos locales y los diversos niveles del gobierno local y de estos con las diversas instancias del Estado central. Esta articulación tiene varias dimensiones como son la planificación, el presupuesto, la gestión de competencias, la información y el intercambio de experiencias. Todos estos aspectos requieren de herramientas técnicas específicas para su manejo.

Todas las condiciones de sostenibilidad son importantes, pero solamente se explican en su articulación y complementariedad permanente. Por ejemplo, la garantía de un proceso sostenido no puede descansar únicamente en las capacidades institucionales sin la existencia de un tejido social, por que la eficiencia lograda se enfrentará con el desconocimiento de la realidad social, con conflictos y con la falta de apoyo al proyecto local. Así mismo, estos dos factores juntos no garantizan sostenibilidad sin la articulación a los procesos regionales y nacionales, pues se toparían con el aislamiento y la falta de apoyo que se requiere provenga de las dimensiones macro territoriales. Lo mismo ocurrirá sin el concurso de las demás condiciones de sostenibilidad señaladas en este documento.

La obtención de logros sostenidos en todos estos campos es el reto de los procesos de desarrollo local. La acción necesaria es amplia y variada y es responsabilidad de la sociedad local, encabezada por sus respectivos gobiernos. El acompañamiento en algunos de estos campos puede hacer y ha hecho de la cooperación técnica de ONGs, OGs y entidades de capacitación, un aporte significativo a los procesos de mejoramiento de la capacidad de instituciones y organizaciones para impulsar el desarrollo local.

El aporte de este documento está en el ámbito de la evaluación que pueden hacerse a si mismos los actores locales, comparando sus logros y procedimientos con los estándares sugeridos en el siguiente capítulo.

\section{Indicadores y estándares del proceso de desarrollo local}

Estándar es la meta o estado de situación que alcanza un indicador para que se pueda considerar que ha tenido un logro significativo. Las alternativas de estándares corresponden a posibles resultados que se pueden alcanzar en las áreas de evaluación, temas significativos e indicadores. Se entiende por indicador al elemento clave que permite observar el desenvolvimiento de un área de evaluación del proceso de desarrollo local.

Los indicadores no abarcan toda la complejidad y calidad del proceso, pero apuntan a un conjunto suficiente de aspectos que permiten medirlo. Por ejemplo el indicador "existencia de un mapa de actores sociales" por si sólo, nada garantiza pero, junto a una "buena organización de la sociedad civil", la "existencia de una instancia de 
coordinación social" y la "adquisición de nuevas capacidades de parte de estas organizaciones", dan una agregación que logra mostrar el avance o freno de un proceso de construcción de tejido social.

La presentación se hace mediante una matriz (ver anexos) en la cual consta el indicador, una breve reflexión sobre el propósito del mismo, la forma de medición del indicador, el estándar esperado y los posibles resultados de la medición de cada indicador. Los resultados pueden desde alcanzar el estándar esperado (e incluso superarlo), hasta encontrar una situación en la cual se esté conspirando contra su logro.

Los posibles resultados están organizados en una escala secuencial que refleja los siguientes estándares de logro de cada indicador:

No hay resultado alguno respecto al indicador: Se usa el "0" (cero), como una alternativa de respuesta cuando hay ausencia de logro.

Resultado bajo respecto al estándar esperado (1): Esto puede significar que todavía este elemento está en una fase inicial o de implementación o no ha logrado todavía alcanzar un estándar aceptable.

Resultado medio (2): Significa que el elemento medido ha alcanzado un nivel que puede ser considerado "en proceso" o aceptable, aunque no haya llegado a niveles de excelencia. En general este estándar muestra que la condición de desarrollo medida se está desenvolviendo.

Estándar alto (3): Quiere decir que este elemento ha logrado un funcionamiento o resultado de calidad $\mathrm{y}$, por lo tanto, coadyuva al logro de un proceso de desarrollo sostenible e institucionalizado.

La obtención de resultados relacionados a estándares altos en varios indicadores, dá indicios de que el proceso está logrando un funcionamiento de excelencia y puede convertirse en un caso exitoso de estudio y observación por parte de otros procesos locales.

En anexo se presentan las matrices con toda la información de indicadores, organizados por áreas de valuación y temas, con sus propósitos, medios de verificación y estándares. 


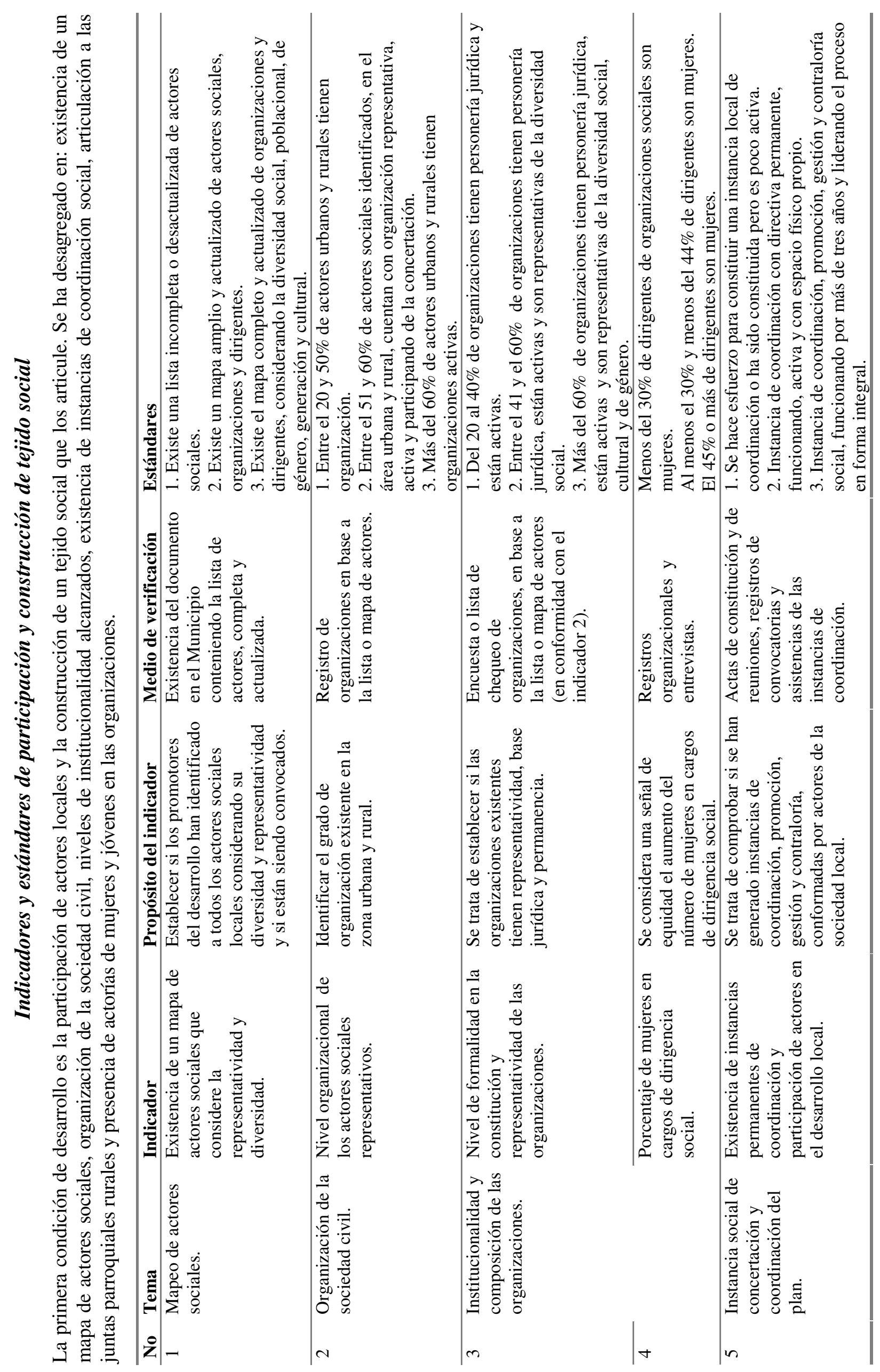




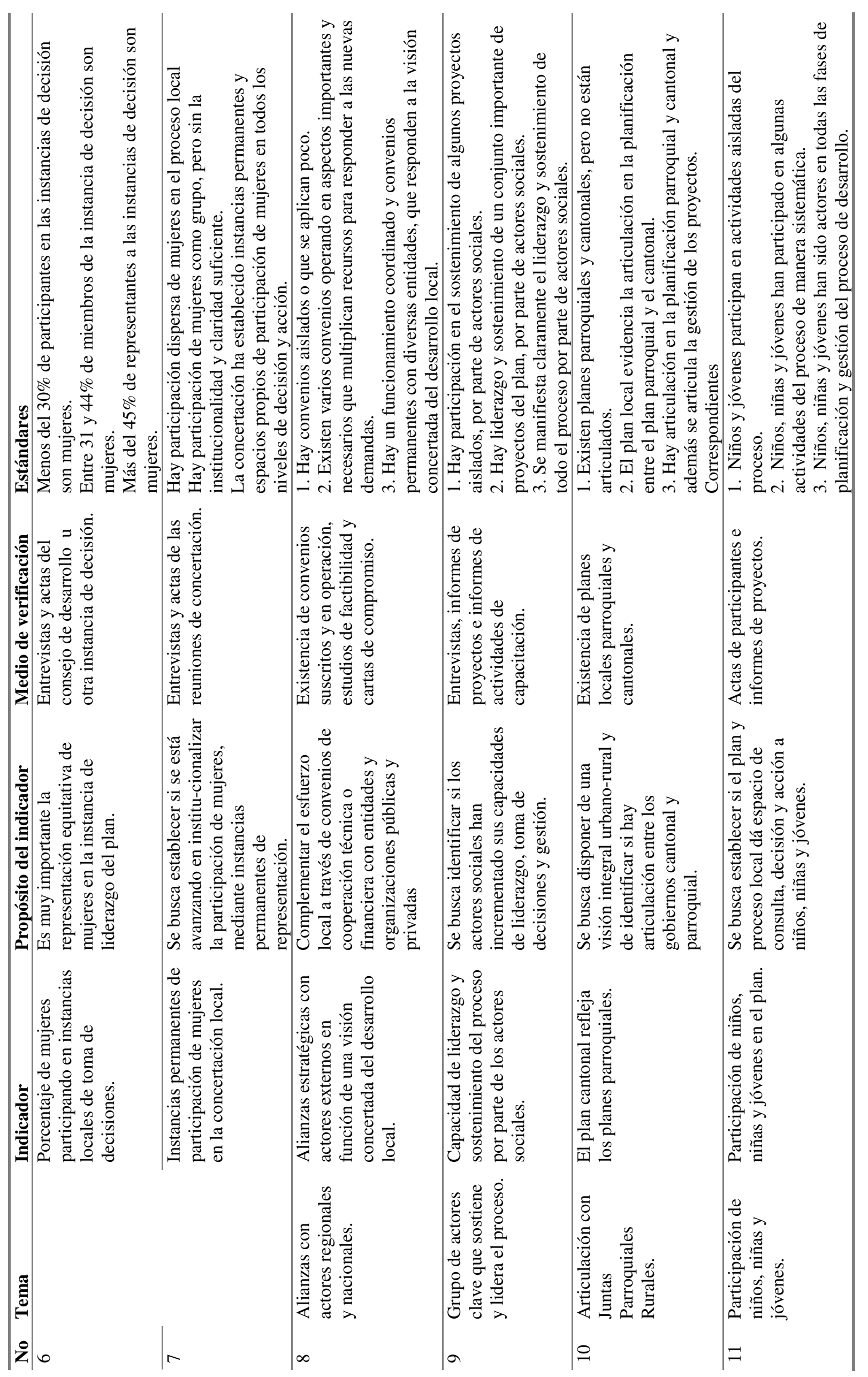




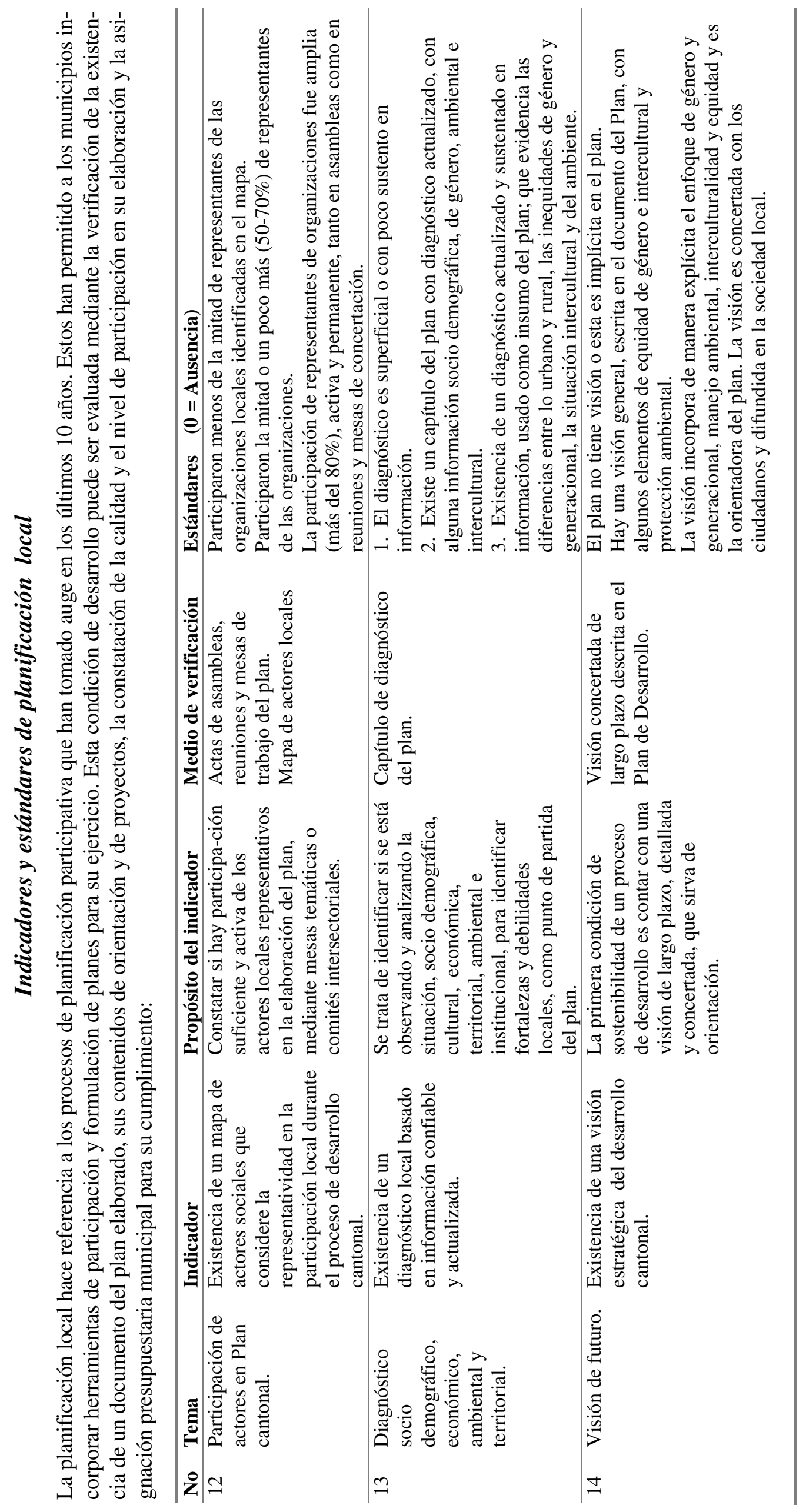




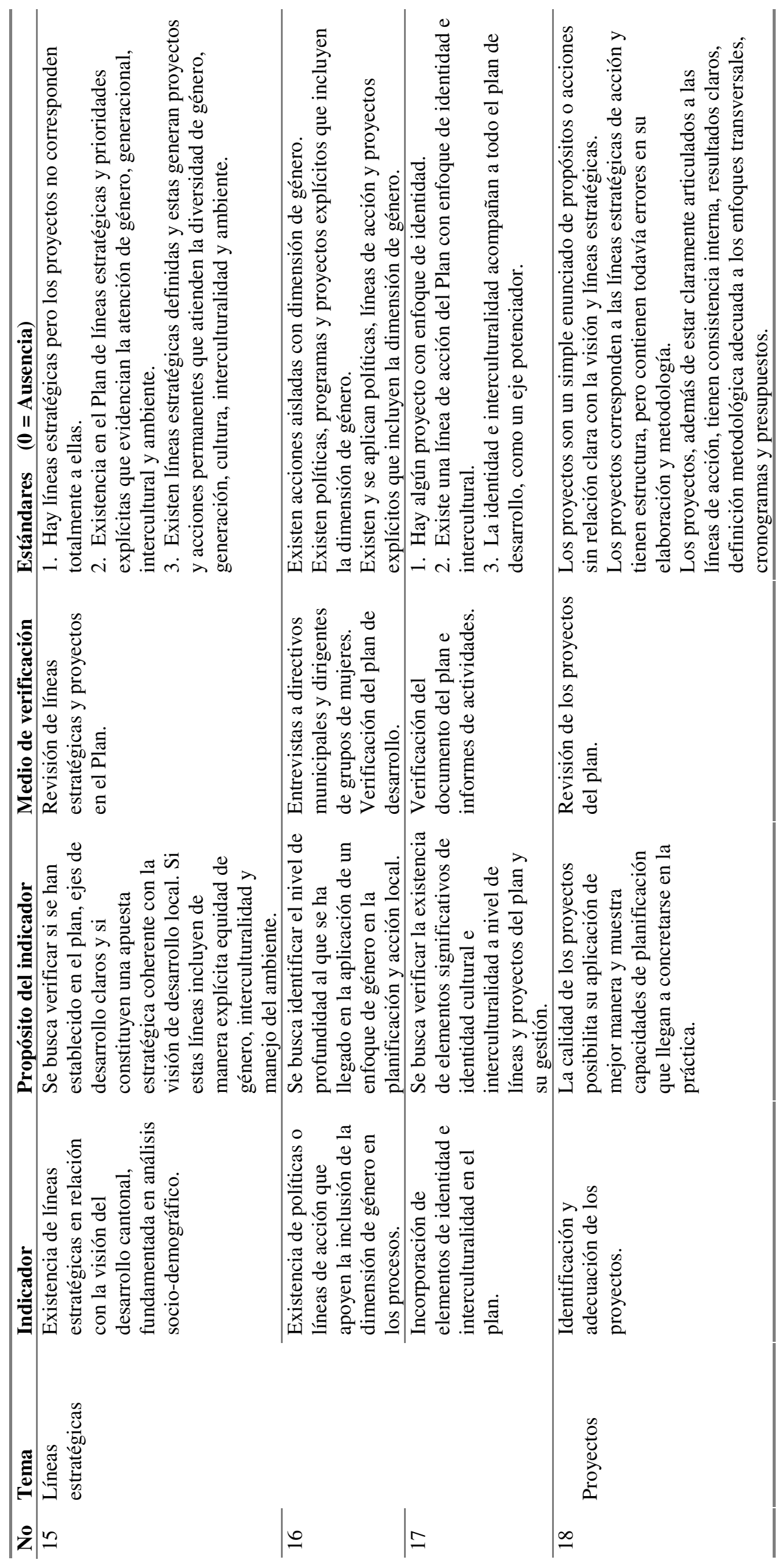




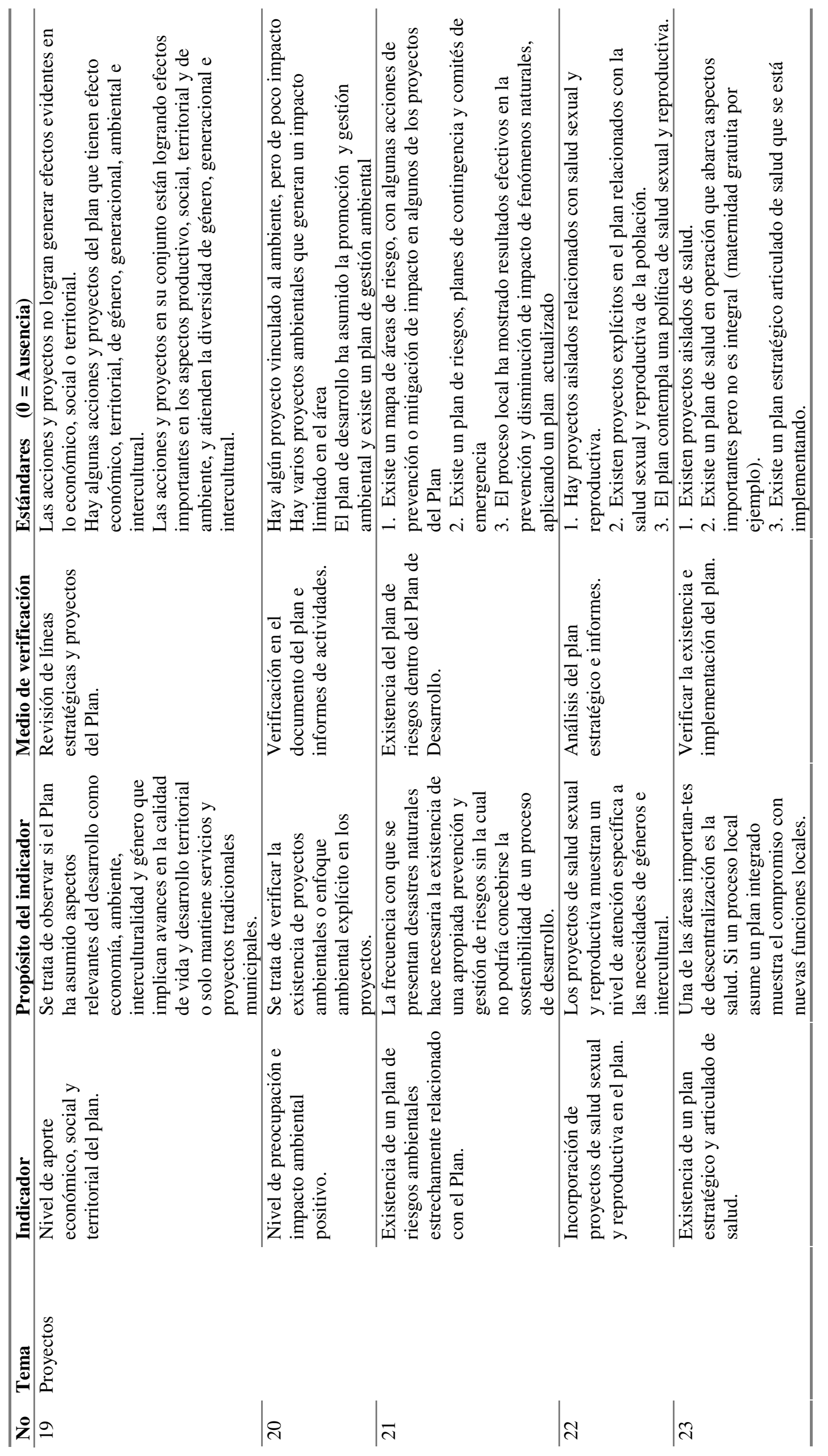




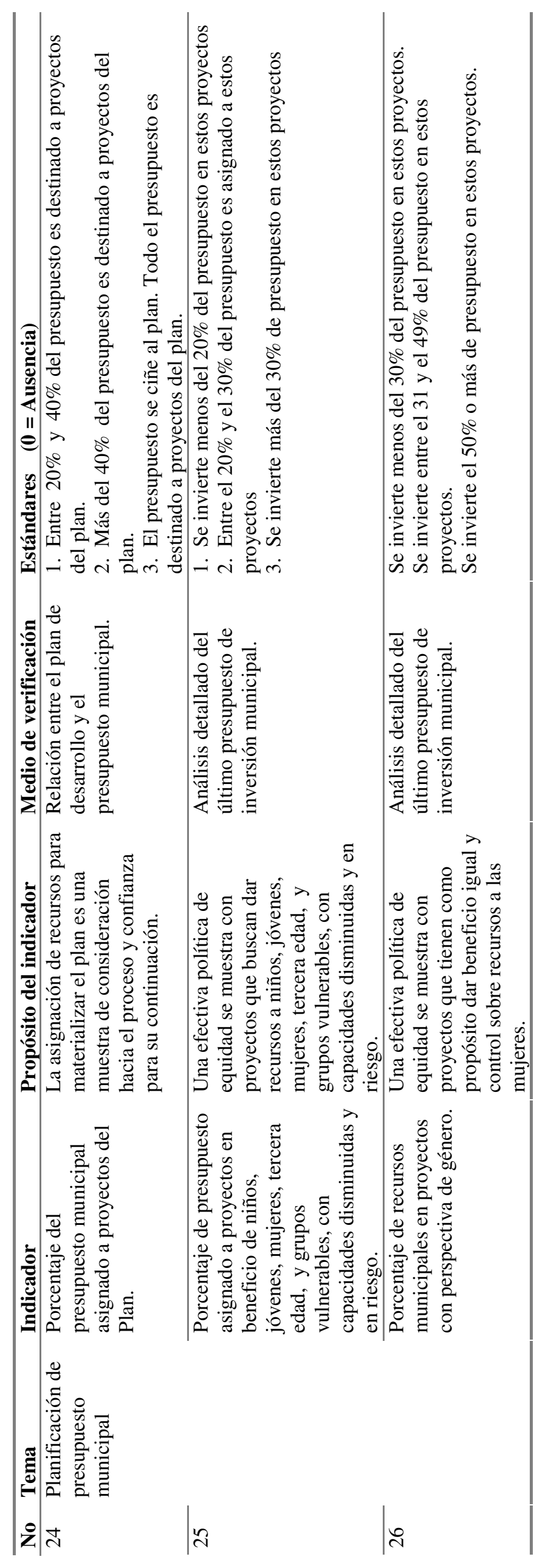




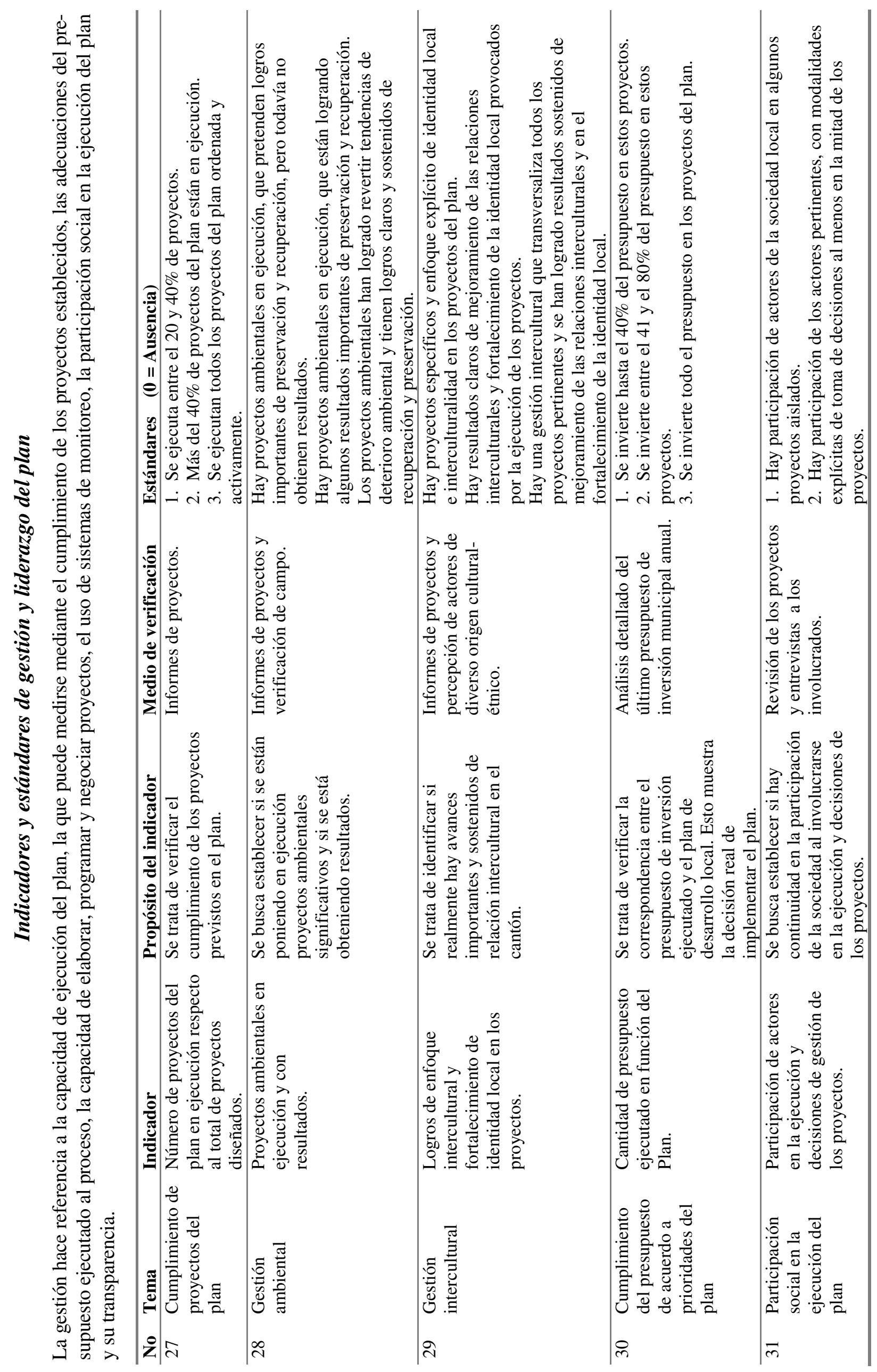




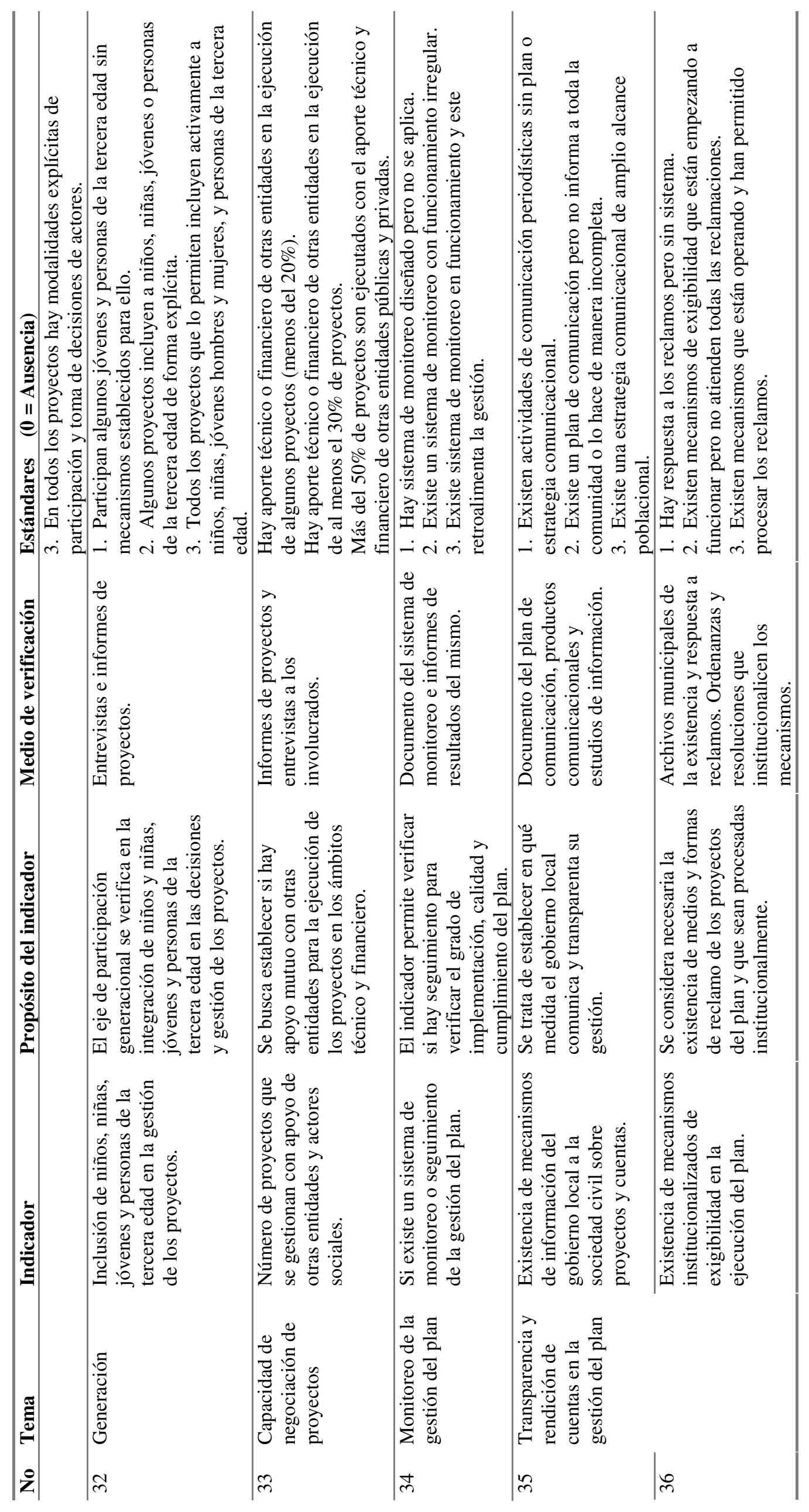




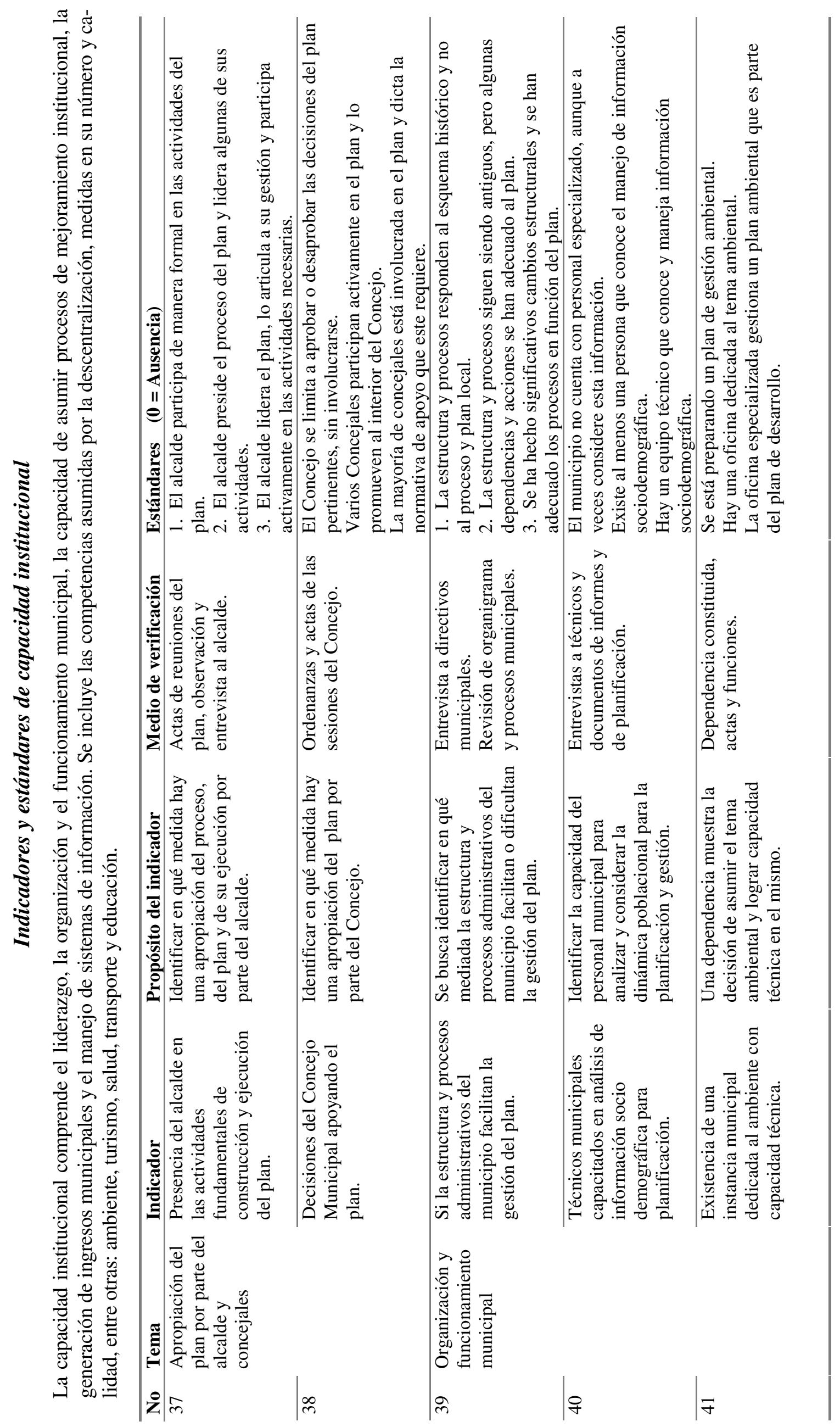




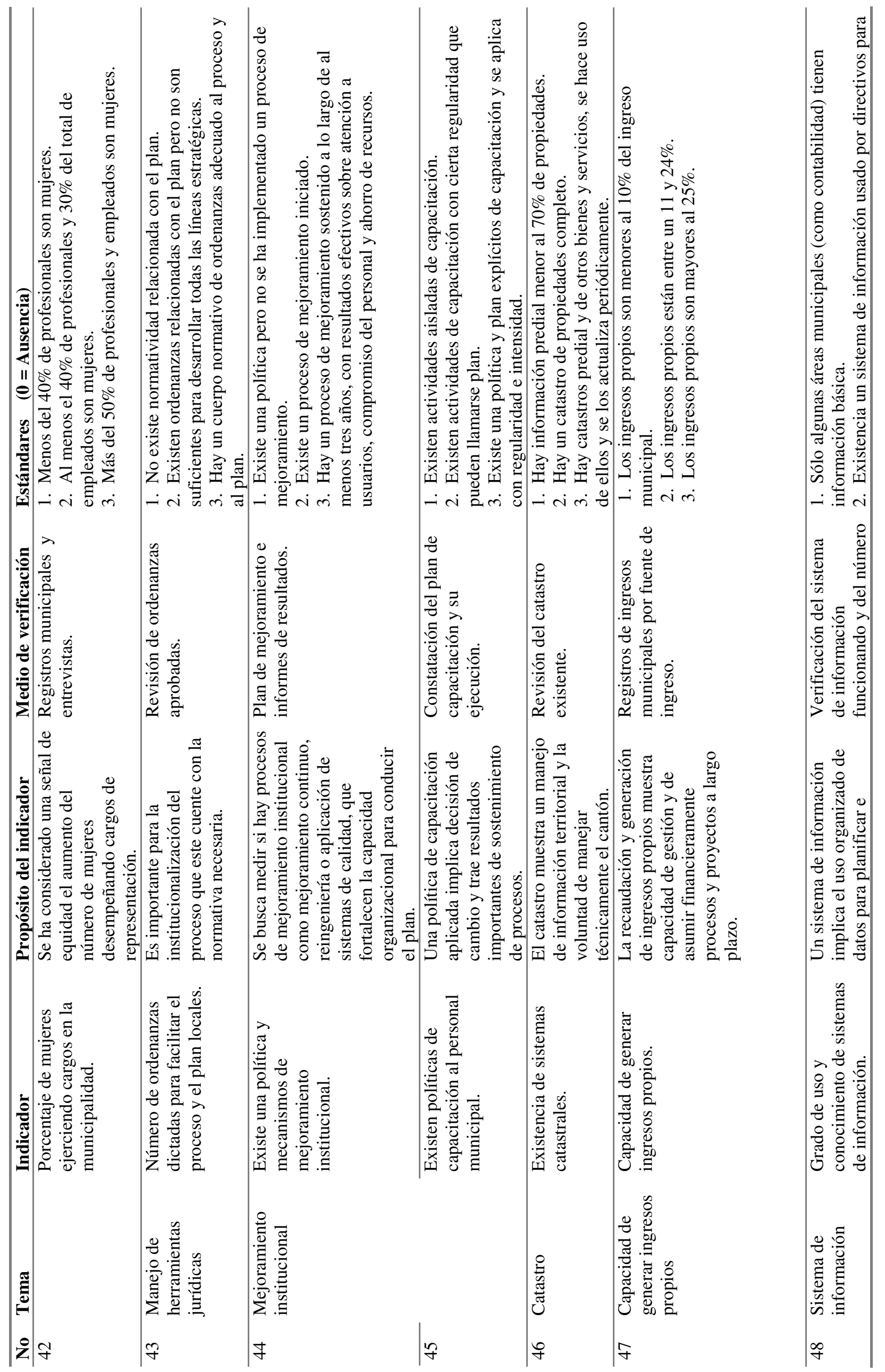




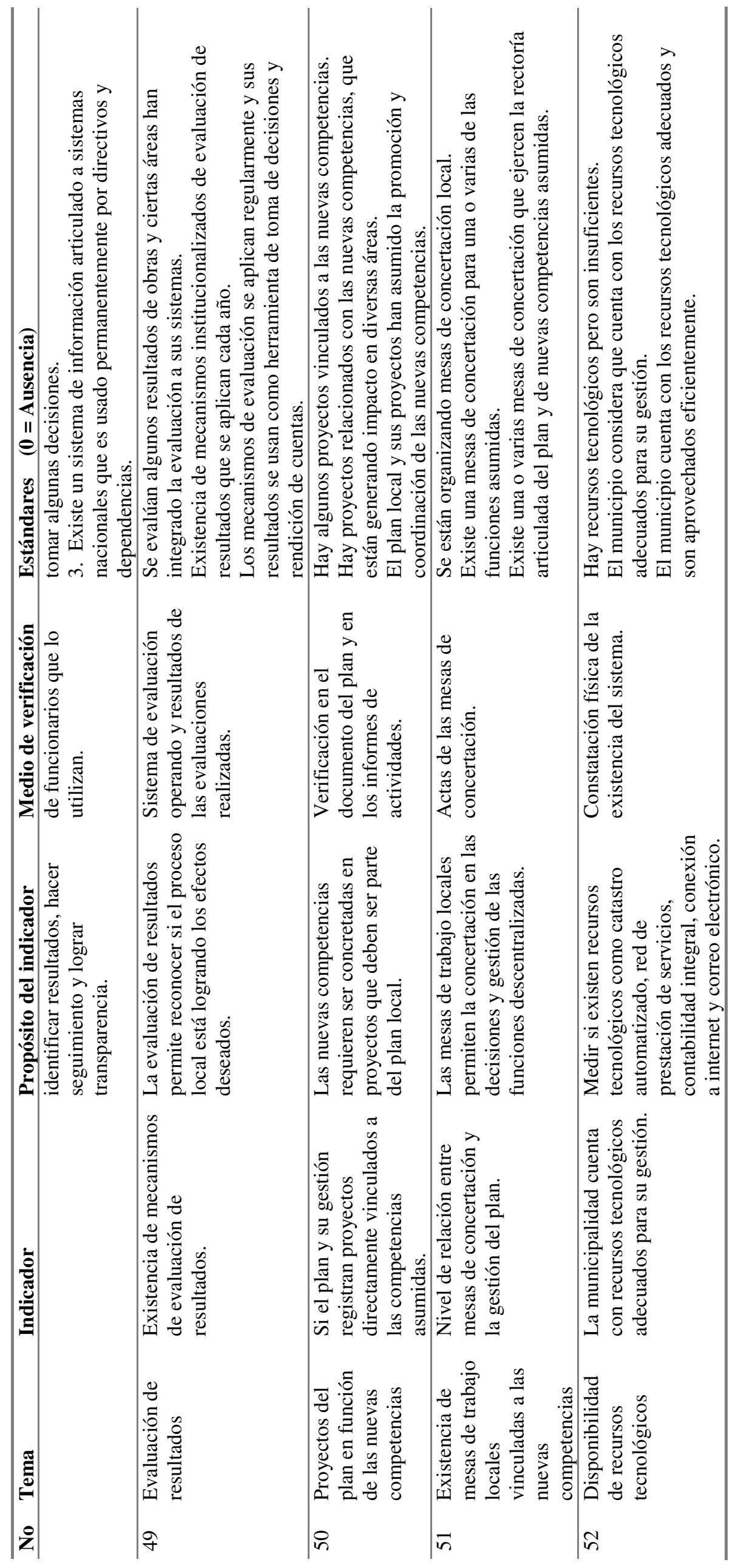




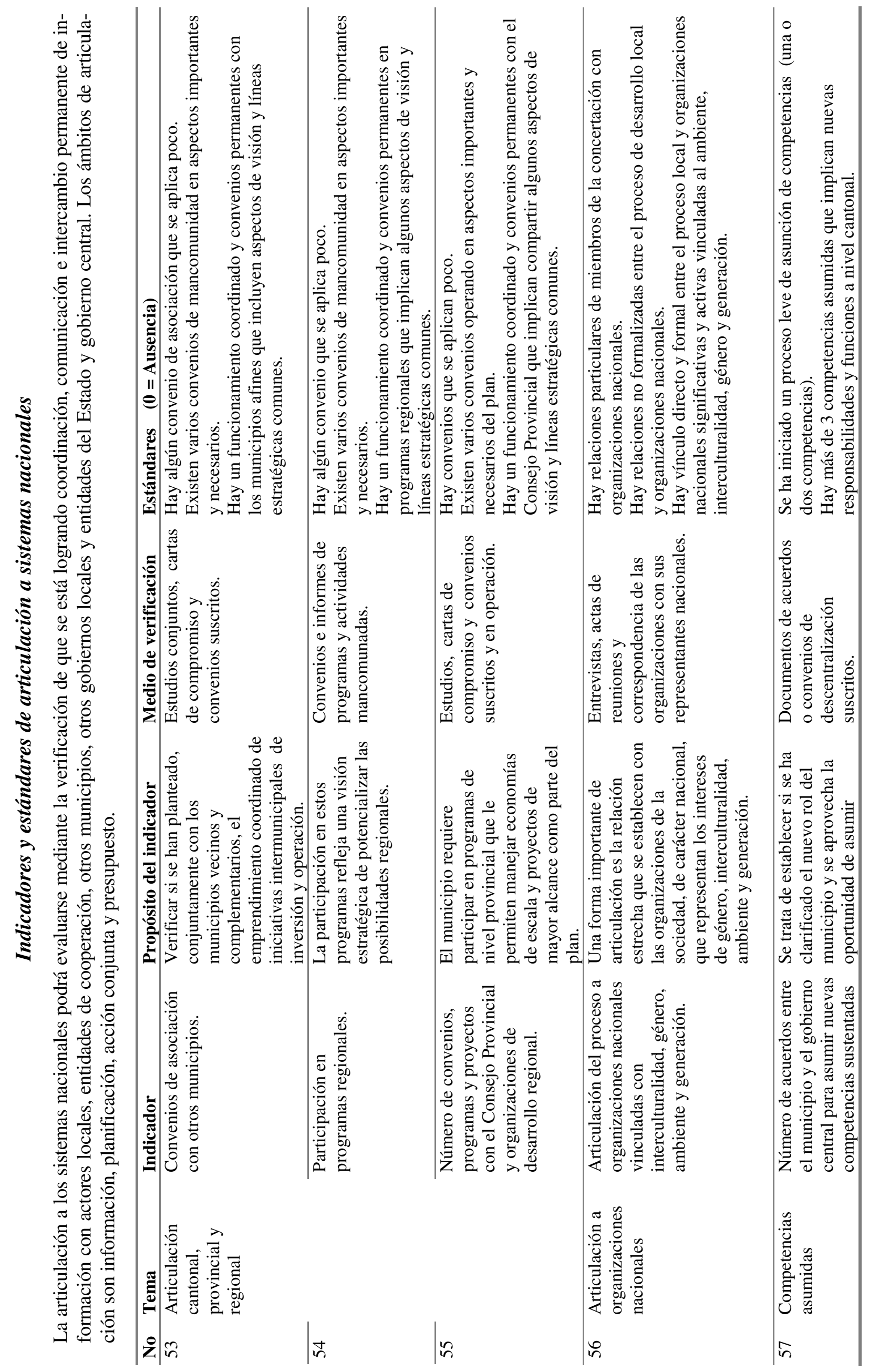




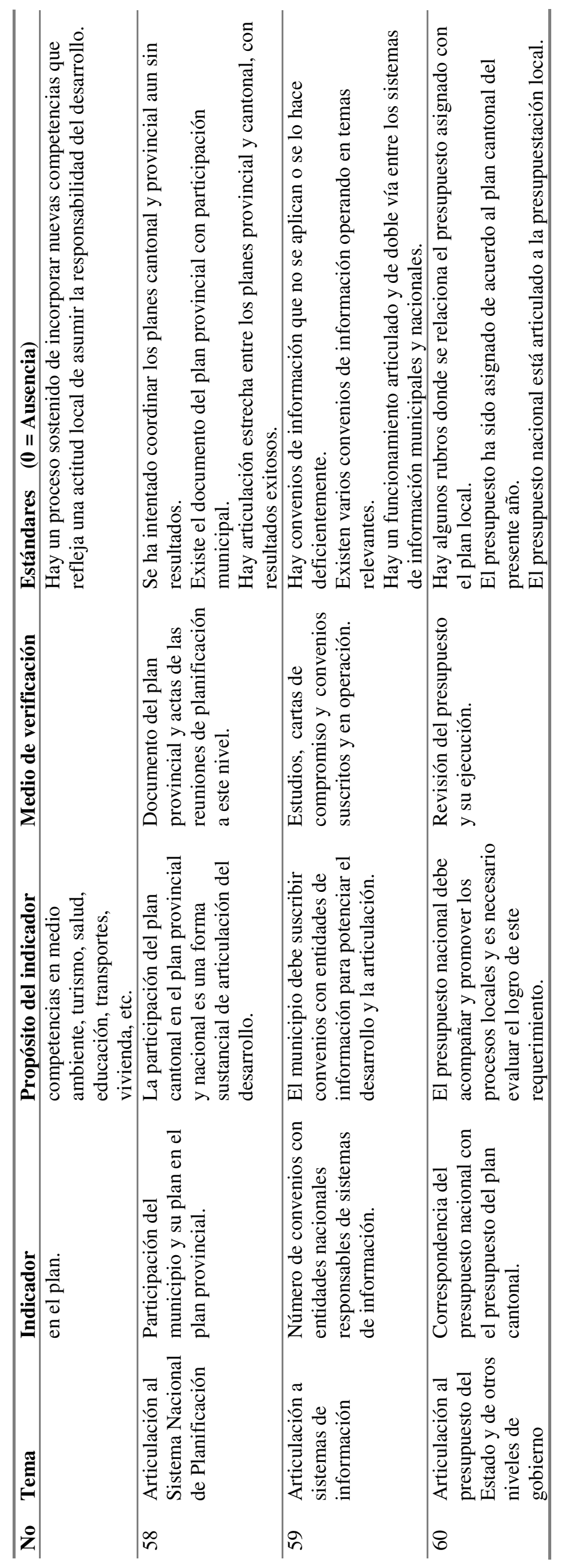




\section{Forma de aplicación}

La aplicación de la evaluación mediante esta metodología de estándares se realiza básicamente en reuniones con grupos de involucrados, los que responden en base a su propia experiencia, reforzados con información objetiva recogida utilizando las fuentes de verificación sugeridas para cada indicador.

Para la aplicación, se utilizan matrices (ver anexo) que permiten visualizar de manera directa el indicador y los tres estándares de respuestas posibles.

Es muy importante lograr de parte del grupo una actitud autocrítica y de busca de objetividad evitando, sobre todo, la normal tendencia a calificarse mejor de lo que realmente se está. La mejor forma de lograr esta objetividad es adjuntar al formulario de aplicación las matrices explicativas de los indicadores, donde se puede consultar el "Propósito del indicador", que permite entender el sentido y profundidad de lo que se quiere conocer.

Se recomienda que, cuando se duda entre una calificación u otra, es mejor poner el puntaje inferior, así la numeración más alta quedará para cuando se pueda mejorar el rendimiento del proceso. Es necesario recordar que la calificación 0 (cero) es también posible, pues indica la ausencia de lo esperado en el estándar mínimo. Así mismo hay que recordar que la calificación 3 significa excelencia y que no puede otorgársela con facilidad. Hay que tomar en cuenta que la calificación 2 es positiva y significa que se encuentran en proceso.

\section{Herramienta de aplicación}

\section{Participación y construcción de tejido social}

\begin{tabular}{|c|c|c|c|c|}
\hline No & Indicador & Estándares $\quad(0=$ Ausencia $)$ & Descripción de la situación & Calif. \\
\hline 1 & $\begin{array}{l}\text { Existencia de un } \\
\text { mapa de actores } \\
\text { sociales que } \\
\text { considere la } \\
\text { representatividad y } \\
\text { diversidad. }\end{array}$ & $\begin{array}{l}\text { Existe una lista incompleta o } \\
\text { desactualizada de actores sociales. } \\
\text { Existe un mapa amplio y actualizado de } \\
\text { actores sociales, organizaciones y } \\
\text { dirigentes. } \\
\text { Existe el mapa completo y actualizado de } \\
\text { organizaciones y dirigentes, considerando } \\
\text { la diversidad de actores sociales, } \\
\text { poblacionales, de género, generacional y } \\
\text { culturales. }\end{array}$ & & \\
\hline 2 & $\begin{array}{l}\text { Nivel organizacional } \\
\text { de los actores sociales } \\
\text { representativos. }\end{array}$ & $\begin{array}{l}\text { Entre el } 20 \text { y } 50 \% \text { de actores urbanos y } \\
\text { rurales tienen organización. } \\
\text { Entre el } 51 \text { y } 60 \% \text { de actores sociales } \\
\text { identificados, en el área urbana y rural, } \\
\text { cuentan con organización representativa, } \\
\text { activa y participando de la concertación. } \\
\text { Más del } 60 \% \text { de actores urbanos y rurales } \\
\text { tienen organizaciones activas. }\end{array}$ & & \\
\hline 3 & $\begin{array}{l}\text { Nivel de formalidad } \\
\text { en la constitución y } \\
\text { representatividad de } \\
\text { las organizaciones. }\end{array}$ & $\begin{array}{l}\text { Del } 20 \text { al } 40 \% \text { de organizaciones tienen } \\
\text { personería jurídica y están activas. } \\
\text { Entre el } 41 \text { y el } 60 \% \text { de organizaciones } \\
\text { tienen personería jurídica, están activas y } \\
\text { son representativas de la diversidad social. } \\
\text { Más del } 60 \% \text { de organizaciones tienen } \\
\text { personería jurídica, están activas y son } \\
\text { representativas de la diversidad social, } \\
\text { cultural y de género. }\end{array}$ & & \\
\hline 4 & $\begin{array}{l}\text { Porcentaje de mujeres } \\
\text { en cargos de } \\
\text { dirigencia social. }\end{array}$ & $\begin{array}{l}\text { Menos del } 30 \% \text { de dirigentes de } \\
\text { organizaciones sociales son mujeres. } \\
\text { Al menos el } 30 \% \text { y menos del } 44 \% \text { de } \\
\text { dirigentes son mujeres. } \\
\text { El } 45 \% \text { o más de dirigentes son mujeres. }\end{array}$ & & \\
\hline
\end{tabular}




\begin{tabular}{|c|c|c|c|c|}
\hline No & Indicador & Estándares $\quad(0=$ Ausencia $)$ & Descripción de la situación & Calif. \\
\hline 5 & $\begin{array}{l}\text { Existencia de } \\
\text { instancias } \\
\text { permanentes de } \\
\text { coordinación y } \\
\text { participación de } \\
\text { actores en el } \\
\text { desarrollo local. }\end{array}$ & $\begin{array}{l}\text { Se hace esfuerzo para constituir una } \\
\text { instancia local de coordinación o ha sido } \\
\text { constituida pero es poco activa. } \\
\text { Instancia de coordinación con directiva } \\
\text { permanente, funcionando, activa y con } \\
\text { espacio físico propio. } \\
\text { Instancia de coordinación, promoción, } \\
\text { gestión y contraloría social, funcionando } \\
\text { por más de tres años y liderando el proceso } \\
\text { en forma integral. }\end{array}$ & & \\
\hline 6 & $\begin{array}{l}\text { Porcentaje de mujeres } \\
\text { participando en } \\
\text { instancias locales de } \\
\text { toma de decisiones. }\end{array}$ & $\begin{array}{l}\text { Menos del } 30 \% \text { de participantes en las } \\
\text { instancias de decisión son mujeres. } \\
\text { Entre } 31 \text { y } 44 \% \text { de miembros de la } \\
\text { instancia de decisión son mujeres. } \\
\text { Más del } 45 \% \text { de representantes a las } \\
\text { instancias de decisión son mujeres. }\end{array}$ & & \\
\hline 7 & $\begin{array}{l}\text { Instancias } \\
\text { permanentes de } \\
\text { participación de } \\
\text { mujeres en la } \\
\text { concertación local. }\end{array}$ & $\begin{array}{l}\text { Hay participación dispersa de mujeres en } \\
\text { el proceso local. } \\
\text { Hay participación de mujeres como grupo, } \\
\text { pero sin la institucionalidad y claridad } \\
\text { suficiente. } \\
\text { La concertación ha establecido instancias } \\
\text { permanentes y espacios propios de } \\
\text { participación de mujeres en todos los } \\
\text { niveles de decisión y acción. }\end{array}$ & & \\
\hline 8 & $\begin{array}{l}\text { Alianzas estratégicas } \\
\text { con actores externos } \\
\text { en función de una } \\
\text { visión concertada del } \\
\text { desarrollo local. }\end{array}$ & $\begin{array}{l}\text { Hay convenios aislados o que se aplican } \\
\text { poco. } \\
\text { Existen varios convenios operando en } \\
\text { aspectos importantes y necesarios que } \\
\text { multiplican recursos para responder a las } \\
\text { nuevas demandas. } \\
\text { Hay un funcionamiento coordinado y } \\
\text { convenios permanentes con diversas } \\
\text { entidades, que responden a la visión } \\
\text { concertada del desarrollo local. }\end{array}$ & & \\
\hline 9 & $\begin{array}{l}\text { Capacidad de } \\
\text { liderazgo y } \\
\text { sostenimiento del } \\
\text { proceso por parte de } \\
\text { los actores sociales. }\end{array}$ & $\begin{array}{l}\text { Hay participación en el sostenimiento de } \\
\text { algunos proyectos aislados, por parte de } \\
\text { actores sociales. } \\
\text { Hay liderazgo y sostenimiento de un } \\
\text { conjunto importante de proyectos del plan, } \\
\text { por parte de actores sociales. } \\
\text { Se manifiesta claramente el liderazgo y } \\
\text { sostenimiento de todo el proceso por parte } \\
\text { de actores sociales. }\end{array}$ & & \\
\hline 10 & $\begin{array}{l}\text { El plan cantonal } \\
\text { refleja los planes } \\
\text { parroquiales. }\end{array}$ & $\begin{array}{l}\text { Existen planes parroquiales y cantonal, } \\
\text { pero no están articulados. } \\
\text { El plan local evidencia la articulación en la } \\
\text { planificación entre el plan parroquial y el } \\
\text { cantonal. } \\
\text { Hay articulación en la planificación } \\
\text { parroquial y cantonal y además se articula } \\
\text { la gestión de los proyectos } \\
\text { correspondientes. }\end{array}$ & & \\
\hline 11 & $\begin{array}{l}\text { Participación de } \\
\text { niños, niñas y jóvenes } \\
\text { en el plan. }\end{array}$ & $\begin{array}{l}\text { 1. Niños y jóvenes participan en } \\
\text { actividades aisladas del proceso. } \\
\text { 2. Niños, niñas y jóvenes han participado } \\
\text { en algunas actividades del proceso de } \\
\text { manera sistemática. } \\
\text { 3. Niños, niñas y jóvenes han sido actores }\end{array}$ & & \\
\hline
\end{tabular}




\begin{tabular}{llll}
\hline No Indicador & Estándares $(0=$ Ausencia $)$ & Descripción de la situación & Calif. \\
\hline & $\begin{array}{l}\text { en todas las fases de planificación y } \\
\text { gestión del procesos de desarrollo. }\end{array}$ & \\
\hline & Total sobre 33 \\
\hline & Porcentaje \\
\hline
\end{tabular}

\section{Cómo hacer el análisis}

Se trata de extraer la información cualitativa que caracterice el estado de situación en cada indicador. Para ello hay que combinar los estándares escogidos con la información escrita en la herramienta de aplicación. Veamos un ejemplo de aplicación:

\section{Participación y tejido social}

\begin{tabular}{|c|c|c|c|}
\hline & Indicador & Descripción de la situación & Puntos \\
\hline 1 & $\begin{array}{l}\text { Mapa de actores sociales que } \\
\text { considere la representatividad y } \\
\text { diversidad. }\end{array}$ & $\begin{array}{l}\text { Existe un mapa actualizado de actores. Falta cubrir el } \\
10 \% \text { del cantón en zonas rurales. }\end{array}$ & 2 \\
\hline 2 & $\begin{array}{l}\text { Actividad y representatividad de las } \\
\text { organizaciones. }\end{array}$ & $\begin{array}{l}\text { Más del } 50 \% \text { de organizaciones están activas y son } \\
\text { representativas de la diversidad social. }\end{array}$ & 2 \\
\hline 3 & $\begin{array}{l}\text { Representación de los sectores más } \\
\text { pobres en las organizaciones locales. }\end{array}$ & $\begin{array}{l}\text { Hay representación de actores sociales pobres } \\
\text { organizados, pero es incompleta por falta de } \\
\text { organización. }\end{array}$ & 1 \\
\hline 4 & $\begin{array}{l}\text { Porcentaje de mujeres en cargos de } \\
\text { dirigencia social. }\end{array}$ & $\begin{array}{l}\text { Menos de la mitad de dirigentes de las organizaciones } \\
\text { activas son mujeres. }\end{array}$ & 1 \\
\hline 5 & $\begin{array}{l}\text { Instancias permanentes de } \\
\text { participación de actores en el } \\
\text { desarrollo local. }\end{array}$ & $\begin{array}{l}\text { Ha sido constituida una instancia local de coordinación } \\
\text { pero no está activa. No convoca. }\end{array}$ & 1 \\
\hline 6 & $\begin{array}{l}\text { Porcentaje de mujeres participando } \\
\text { en instancias locales de toma de } \\
\text { decisiones. }\end{array}$ & $\begin{array}{l}\text { Como no está activa la instancia, no se puede medir la } \\
\text { participación de las mujeres. }\end{array}$ & 0 \\
\hline 7 & $\begin{array}{l}\text { Instancias permanentes de } \\
\text { participación de mujeres en la } \\
\text { concertación local. }\end{array}$ & $\begin{array}{l}\text { Hay participación de mujeres como grupo, pero sin la } \\
\text { institucionalidad y claridad suficiente. }\end{array}$ & 1 \\
\hline 8 & $\begin{array}{l}\text { Alianzas estratégicas de asociación } \\
\text { con actores provinciales, nacionales e } \\
\text { internacionales. }\end{array}$ & $\begin{array}{l}\text { Existen varios convenios operando lo que ha permitido } \\
\text { incrementar los recursos y responder a nuevas } \\
\text { demandas. Sin embargo falta coordinación dentro del } \\
\text { municipio, que no logra responder a todos los } \\
\text { convenios. }\end{array}$ & 2 \\
\hline 9 & $\begin{array}{l}\text { Capacidad de liderazgo y } \\
\text { sostenimiento del proceso por parte } \\
\text { de los actores sociales. }\end{array}$ & $\begin{array}{l}\text { Hay participación en el sostenimiento de proyectos } \\
\text { aislados, por parte de algunos actores sociales. }\end{array}$ & 1 \\
\hline 10 & $\begin{array}{l}\text { El plan municipal refleja los planes } \\
\text { comunitarios. }\end{array}$ & $\begin{array}{l}\text { El plan local evidencia la articulación de planes } \\
\text { comunitarios. }\end{array}$ & 2 \\
\hline 11 & $\begin{array}{l}\text { Participación de niños, niñas y } \\
\text { jóvenes en el plan. }\end{array}$ & $\begin{array}{l}\text { Los niños, niñas y jóvenes han participado de manera } \\
\text { organizada en el plan y están siendo parte de la gestión } \\
\text { de los proyectos. }\end{array}$ & 2 \\
\hline & Total sobre 33 & & 15 \\
\hline & Porcentaje & & $45.5 \%$ \\
\hline
\end{tabular}

Una forma de análisis o interpretación de los resultados puede ser el establecer que, cuando el resultado es bajo ( 0 a 33\%), el proceso no se sostiene o está en riesgo de retroceder. Cuando el resultado es medio (34 a 66\%) se están construyendo condiciones para lograr sostenibilidad y, cuando es alto (67 a 100\%), el proceso ha logrado sostenibilidad. 
La medición efectuada ha sido organizada en cinco áreas de evaluación conteniendo cada una el siguiente número de indicadores y los posibles resultados de medición de 0 a 3 en cada indicador ${ }^{2}$.

\begin{tabular}{lccccc}
\hline & Indicadores & $\begin{array}{c}\text { Puntaje } \\
\text { máximo }\end{array}$ & $\begin{array}{c}\text { Resultado } \\
\text { bajo }\end{array}$ & $\begin{array}{c}\text { Resultado } \\
\text { medio }\end{array}$ & $\begin{array}{c}\text { Resultado } \\
\text { alto }\end{array}$ \\
\hline Participación y tejido social & 11 & 33 & $0-11$ & $12-22$ & $23-33$ \\
\hline Planificación & 15 & 45 & $0-15$ & $16-30$ & $31-45$ \\
\hline Gestión del plan & 10 & 30 & $0-10$ & $11-20$ & $21-30$ \\
\hline Capacidad institucional & 16 & 48 & $0-16$ & $17-32$ & $33-48$ \\
\hline Articulación nacional & 8 & 24 & $0-8$ & $9-16$ & $17-24$ \\
\hline Total & 60 & 180 & $0-60$ & $61-120$ & $121-180$ \\
\hline
\end{tabular}

Así mismo, se han construido cuatro ámbitos de análisis con los ejes transversales con el siguiente número de indicadores en cada uno:

\begin{tabular}{lccccc}
\hline & Indicadores & $\begin{array}{c}\text { Puntaje } \\
\text { máximo }\end{array}$ & $\begin{array}{c}\text { Resultado } \\
\text { bajo }\end{array}$ & $\begin{array}{c}\text { Resultado } \\
\text { medio }\end{array}$ & $\begin{array}{c}\text { Resultado } \\
\text { alto }\end{array}$ \\
\hline Género & 11 & 33 & $0-11$ & $12-22$ & $23-33$ \\
\hline Ambiente & 7 & 21 & $0-7$ & $8-14$ & $15-21$ \\
\hline Interculturalidad & 7 & 21 & $0-7$ & $8-14$ & $15-21$ \\
\hline Generación & 7 & 21 & $0-7$ & $8-14$ & $15-21$ \\
\hline
\end{tabular}

Para el procesamiento cuantitativo se puede utilizar la propia herramienta de aplicación de la evaluación, o se puede pasar la información a una hoja electrónica.

Como ejemplo, se establecen los siguientes resultados:

\begin{tabular}{lccc}
\hline Componente & Resultado & Sobre & Porcentaje \\
\hline Total & 58 & 168 & $32.2 \%$ \\
\hline Tejido Social & 14 & 33 & $42.4 \%$ \\
\hline Planificación & 14 & 45 & $31.1 \%$ \\
\hline Gestión & 8 & 30 & $26.7 \%$ \\
\hline Capacidad Instit. & 16 & 48 & $33.3 \%$ \\
\hline Articul. Nacional & 6 & 24 & $25.0 \%$ \\
\hline Género & 8 & 33 & $27.3 \%$ \\
\hline Ambiente & 6 & 21 & $28.6 \%$ \\
\hline Interculturalidad & 6 & 21 & $28.6 \%$ \\
\hline Generación & 6 & 21 & $28.6 \%$ \\
\hline
\end{tabular}

Con este resultado se tendrá una imagen gráfica del estado de situación de la gestión municipal, desagregada en sus diversos componentes.

\footnotetext{
${ }^{2}$ No se ha establecido el número de indicadores de las áreas para darle a cada una peso específico. Así mismo no se está dando para el procesamiento ninguna ponderación a cada indicador, sino que su peso está dado por la calificación de 0 a 3 exclusivamente.
} 
Evaluación de la Gestión de Desarrollo Local

Total

Tejido Social

$\square$ Planificación

$\square$ Gestión

$\square$ Capacidad Instit.

$\square$ Articul. Nacional

\section{$\square$ Género}

$\square$ Ambiente

$\square$ Interculturalidad

$\square$ Generación

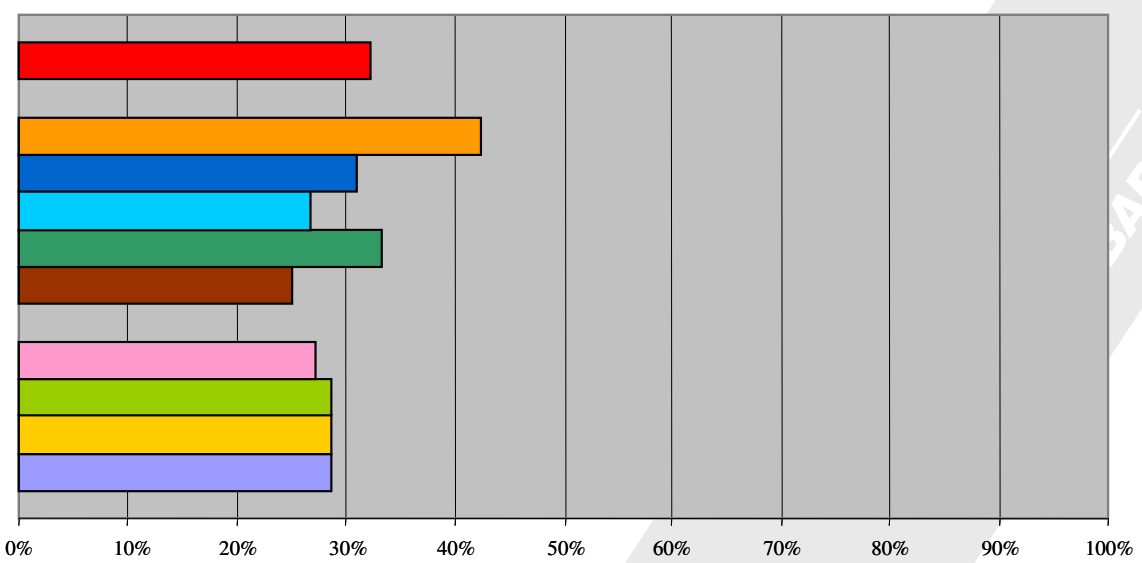

\section{Línea de base y línea de avance}

La cuantificación permite al proceso identificar su estado de situación inicial y graficarlo en un eje de coordenadas (línea de base). Usando esta forma de procesamiento se pueden establecer también series en el tiempo, de acuerdo a la evolución del proceso detectada en sucesivas mediciones. En este sentido, se sugiere hacer mediciones periódicas, empezando con la línea de base que permite establecer un punto de partida y, a partir de ésta, realizar mediciones periódicas (cada 3 o 4 meses), obteniendo así una línea de avance.

A continuación se presenta un ejemplo de medición frecuente que permite obtener líneas de avance o series estadísticas como la siguiente:

\begin{tabular}{lccccc}
\hline & Línea de base & \multicolumn{4}{c}{ Línea de avance } \\
\hline Área de evaluación & $\mathbf{1}^{\mathbf{a}}$ medición & $\mathbf{2}^{\mathbf{a}}$ medición & $\mathbf{3}^{\text {a }}$ medición & $\mathbf{4}^{\mathbf{a}}$ medición & $\mathbf{5}^{\mathbf{a}}$ medición \\
\hline Total & 32.2 & 37.3 & 42.0 & 51.7 & 70.4 \\
\hline Participación y tejido social & 42.3 & 52.0 & 57.3 & 69.9 & 78.8 \\
\hline Planificación & 31.1 & 54.7 & 57.3 & 63.7 & 67.4 \\
\hline Gestión del plan & 26.7 & 36.7 & 45.4 & 57.2 & 65.0 \\
\hline Capacidad institucional & 33.3 & 36.6 & 46.5 & 58.1 & 70.3 \\
\hline Articulación nacional & 25.0 & 26.0 & 31.7 & 41.5 & 54.5 \\
\hline
\end{tabular}

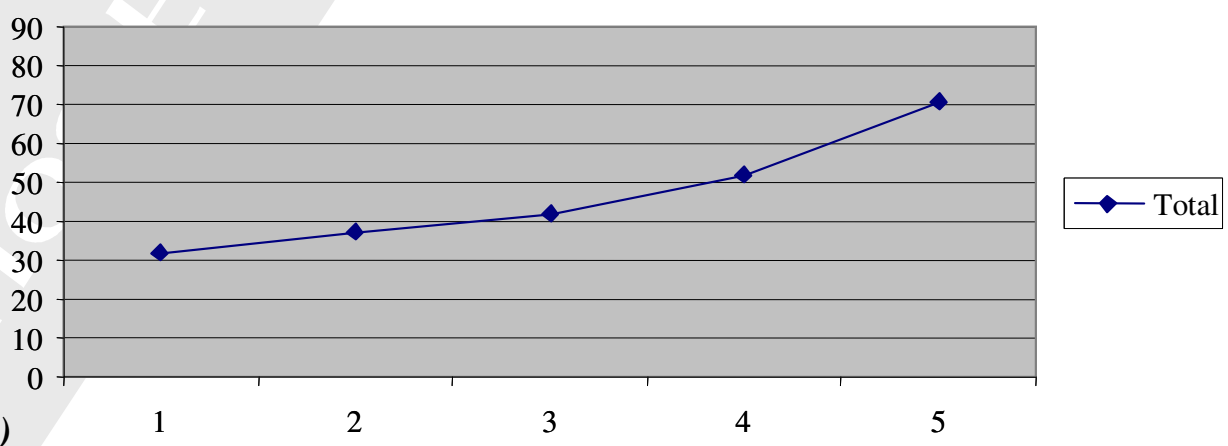




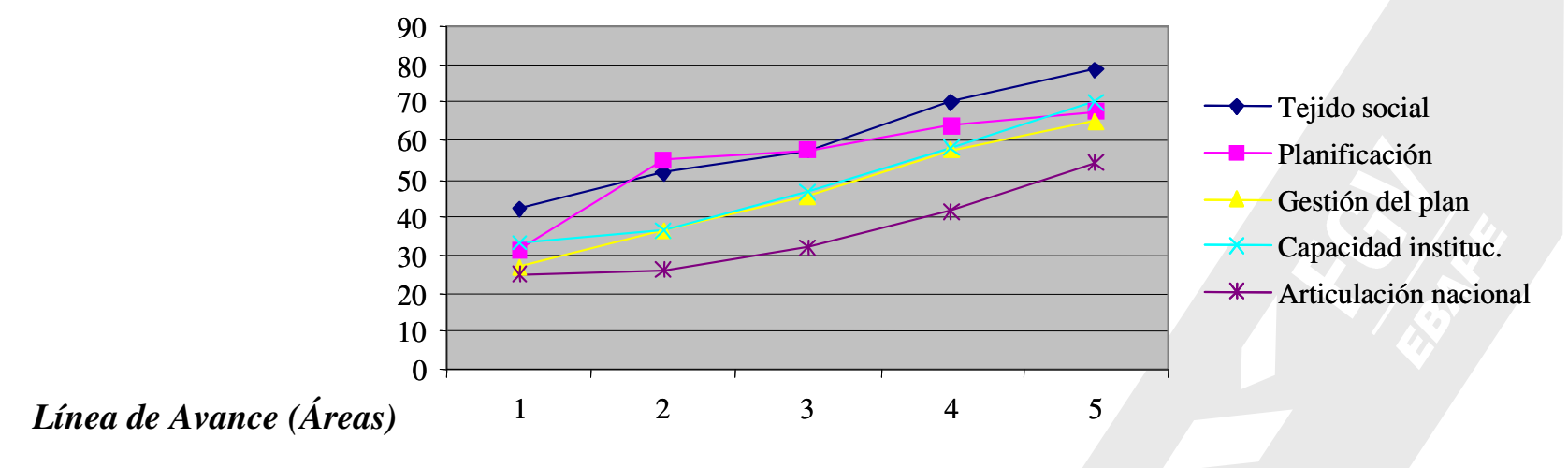

Una medición frecuente permitirá a los actores y líderes del proceso fortalecerlo y optimizar recursos. Se podrá identificar en que áreas se están logrando avances y cuales están detenidas. Se pueden identificar fortalezas y debilidades de los procesos a lo largo del tiempo.

\section{Análisis cualitativo de la información}

El análisis de los resultados de esta evaluación debe ser siempre relativo al contexto y condiciones propias del proceso de desarrollo local y no se debe relacionar con una lectura mecánica de los resultados. Lo primero a tomar en cuenta es que los resultados son más que nada una oportunidad para la reflexión y que esta es más importante que aquellos. Por eso se sugerirá más adelante hacer un proceso de construcción colectiva del análisis.

Hay que tener siempre presente que el objeto de este análisis es la gestión del desarrollo y no el desarrollo mismo. Esto quiere decir que un buen resultado muestra que hay capacidades para enfrentar y promover el desarrollo, pero no por ello se encontrarán necesariamente altos estándares de vida, sobre todo en procesos más jóvenes, en zonas más pobres o donde las condiciones de vida son más difíciles. La gestión y el desarrollo están vinculados pero no tienen un resultado mecánico.

También hay que tomar en cuenta que, al tratase de una autoevaluación, siempre habrá condiciones de subjetividad o posibles sesgos en la percepción. Desde una percepción cultural, hay zonas donde el significado de las palabras utilizadas en los indicadores y estándares es distinto o los niveles de exigencia son mayores. Por ejemplo los estándares de calificación "3" pretender reflejar excelencia, lo que no siempre es comprendido en la autocalificación.

El análisis cualitativo de resultados tiene dos fases importantes. La primera consiste en la descripción de la situación, mediante la descripción del resultado de cada indicador. La lectura vertical de la columna correspondiente en la hoja de respuestas, permite tener un breve estado de situación de cada área de evaluación. Por su parte, se puede hacer una comparación del resultado con el estándar de excelencia, dentro de cada indicador, estableciendo la brecha respectiva. Brecha es la distancia existente entre el resultado deseado en cada indicador y el resultado real obtenido mediante la medición.

La segunda fase de análisis es un proceso de reconstrucción colectiva que consiste en una reunión con actores donde se presentan los resultados y se reflexiona sobre el alcance de los mismos, la situación del proceso de desarrollo local y las perspectivas y decisiones que hay que tomar hacia el futuro. Este es un momento muy importante, pues permite reflexionar sobre la práctica pasada y presente, en función de enriquecerla para el futuro.

Este análisis debe identificar los aspectos fuertes del proceso, mediante la identificación de líneas exitosas de acción para afincarse en ellas. Así mismo, debe encontrar las debilidades críticas para actuar sobre ellas. Se trata de comprender la lógica del proceso y lograr un aprendizaje de lo sucedido. En una reunión de reconstrucción colectiva, por ejemplo, se puede trabajar con una matriz como la siguiente: 


\begin{tabular}{ccccc}
\hline $\begin{array}{c}\text { Áreas de } \\
\text { evaluación del } \\
\text { desarrollo local }\end{array}$ & $\begin{array}{c}\text { Resultado logrado } \\
\text { (brechas) }\end{array}$ & $\begin{array}{c}\text { Funcionamiento de la } \\
\text { gestión y momentos } \\
\text { críticos }\end{array}$ & $\begin{array}{c}\text { Cambios en el } \\
\text { contexto y en los } \\
\text { actores }\end{array}$ & $\begin{array}{c}\text { Lecciones aprendidas, } \\
\text { fortalezas, debilidades } \\
\text { y hallazgos }\end{array}$ \\
\hline
\end{tabular}

Las decisiones para fortalecer el proceso de desarrollo local pueden estar en el ámbito de cambios en objetivos, estrategias y metodologías; en la necesidad de cambios de actitud de los actores, o; decisiones referidas a cambios en la gestión del proceso, en su conducción, en la reorganización de espacios, en los movimientos de personal, en la reasignación de recursos, etc.

Otra forma de análisis es realizar una visión del conjunto para ver que tipo de proceso se está privilegiando. Para facilitar este análisis, hemos desarrollado algunos modelos de interpretación que se presentan a continuación.

\section{Modelos de procesos locales a partir de la metodología de estándares}

Analizando los resultados se puede caracterizar a cada área de evaluación por un desempeño alto, medio o bajo. En cada uno de estos modelos encontraremos tendencias para obtener logros en algunas áreas del proceso de desarrollo y debilidades claras en otras. Los resultados rebasan los indicadores y estándares aquí propuestos, pero han podido se identificados mediante ellos. Las situaciones típicas de nuestro medio pueden ser:

\section{Procesos exitosos:}

a) Procesos exitosos sostenidos

\begin{tabular}{|c|c|c|c|}
\hline Área de evaluación & Bajo & Medio & Alto \\
\hline \multicolumn{4}{|c|}{ Construcción de tejido social } \\
\hline \multicolumn{4}{|l|}{ Planificación local } \\
\hline \multicolumn{4}{|l|}{ Gestión del plan } \\
\hline Capacidad institucional & & & \\
\hline Articulación nacional & & & \\
\hline
\end{tabular}

Un proceso exitoso se caracteriza por tener logros importantes en todas las áreas evaluadas y articulación entre ellas. Su tejido social es fuerte y ha incorporado activamente a la mayor parte de actores sociales locales, a la vez que estos se encuentran trabajando con planes integrados entre si. Cuentan con una instancia de coordinación, con un espacio de independencia, a la vez, funciona articulado al municipio. Sus dirigentes se preparan y obtienen nuevos aprendizajes permanentemente y aportan todos al proceso de desarrollo local, además de vigilarlo y darle continuidad cada vez que hay cambio de autoridades locales. En este sentido cumplen un papel de inducción a la nuevas autoridades hacia el proceso que se ha planificado concertadamente. Además hay varios convenios de acción interinstitucionales e inter-actores y se registra un funcionamiento articulado entre el municipio y las juntas parroquiales.

La planificación local es resultado del buen funcionamiento del tejido social y responde al interés común identificado por la concertación. El plan participativo es de largo alcance, tiene apuestas estratégicas e incluye la asunción de nuevas funciones por la descentralización. Sus proyectos impulsan aspectos centrales del desarrollo y están siendo gestionados con éxito y eficiencia. La gestión del plan es liderada por el municipio pero su acción la comparten todas las entidades de desarrollo y actores locales, logrando durante su operación concretar resultados positivos de equidad, de género, de interculturalidad, de manejo de recursos ambientales y de apoyo a sectores desfavorecidos. Los proyectos funcionan bien, tienen una alta participación social en su implementación e incluso, se ha logrado afrontar con previsión riesgos naturales ocurridos. Todo el presupuesto de inversión municipal y de las entidades de desarrollo está siendo ejecutado en función de los proyectos del plan y los 
proyectos en general son conocidos y su manejo es transparente; además todos ellos informan a la comunidad en momentos previstos para ello.

El municipio lidera el proceso, compartiendo el espacio con los demás actores. Las autoridades locales tienen una imagen positiva dentro de su medio y tienen liderazgo y control en sus respectivas instituciones. Los funcionarios municipales y de otras instituciones, donde hay equilibrio en el aporte de los diferentes grupos, mujeres y hombres y diversas etnias, se están preparando y trabajan integrados a la sociedad, cumpliendo sus funciones y tomando iniciativas en base a sistemas diseñados por ellos mismo. Todas las entidades se encuentran en procesos de mejoramiento con alta participación de su personal y de sus usuarios respectivos.

Esto configura entidades efectivas, que obtienen sus resultados, que trabajan junto a sus usuarios y que logran el sostenimiento económico de sus actividades. Trabajan con sistemas de información, monitoreo y evaluación, articulados a otras entidades e instancias de nivel regional y nacional. El proceso local se articula, nutre y aporta a los procesos provinciales, regionales y nacional, mediante el aporte mutuo de recursos y capacidades, sistemas de planificación, información, monitoreo y evaluación, transparente manejo del presupuesto del Estado, apoyo técnico e intercambio de experiencias; todo en el marco de un desarrollo nacional articulado.

b) Procesos exitosos de un único período

\begin{tabular}{|c|c|c|c|}
\hline Área de evaluación & Bajo & Medio & Alto \\
\hline \multicolumn{4}{|c|}{ Construcción de tejido social } \\
\hline Planificación local & & & \\
\hline Gestión del plan & & & \\
\hline Capacidad instituciona & & & \\
\hline Articulación nacional & & & \\
\hline
\end{tabular}

Cuando se cuenta con un único período corto para llevar adelante un proceso, lo más común es que se refuercen los procesos de participación, de planificación y en parte, de gestión.

Los procesos exitosos de un único período, a diferencia del escenario anterior, no han tenido tiempo suficiente de consolidar algunos de los aspectos señalados, sobre todo en los ámbitos de incremento de las capacidades institucionales, de asunción de competencias y de articulación a niveles regionales y nacionales, ya que son elementos que requieren de mayor tiempo para implementarlos.

La gestión del plan y el manejo de temas transversales puede, en conjunto, ser medio o incluso, alcanzar los estándares, dependiendo de la capacidad y la visión de las personas que conducen el proceso.

\section{Procesos intermedios:}

Los procesos intermedios suelen tener una orientación de cambio, pero generalmente privilegian una de estas dos situaciones: el manejo técnico o tecnocrático o la alta participación pero sin mucho sistema.

a) Procesos intermedios tecnocráticos (mucha planificación y poca participación)

\begin{tabular}{|c|c|c|c|}
\hline Área de evaluación & Bajo & Medio & Alto \\
\hline \multicolumn{4}{|c|}{ Construcción de tejido social } \\
\hline \multicolumn{4}{|l|}{ Planificación local } \\
\hline \multicolumn{4}{|l|}{ Gestión del plan } \\
\hline Capacidad institucional & & & \\
\hline Articulación nacional & & & \\
\hline
\end{tabular}

En estos procesos, las áreas más desarrolladas son las referidas a la elaboración y gestión del plan, aunque no sean muy participativos, sobre todo en la gestión. La capacidad institucional es al menos media, se tiende a asumir competencias relacionadas con servicios básicos y control y hay cierta articulación nacional, sobre todo, para obtener recursos del gobierno central y de otras fuentes financieras. 
La participación tiende a ser baja o se la reconoce como "aporte comunitario a los proyectos municipales" sin entrar en aspectos decisionales. Este manejo, desde lo técnico,también conduce a considerar poco la incorporación de temas transversales los que generalmente están más relacionados con un enfoque en participación.

Este "modelo" puede tener muchas variantes pero el eje no cambia y el control del proceso es realizado desde los mandos técnicos del municipio.

b) Procesos intermedios activistas (mucha participación pero poco resultado)

\begin{tabular}{|c|c|c|c|}
\hline Área de evaluación & Bajo & Medio & Alto \\
\hline \multicolumn{4}{|c|}{ Construcción de tejido social } \\
\hline Planificación local & & & 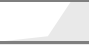 \\
\hline Gestión del plan & & & \\
\hline Capacidad institucional & & & \\
\hline Articulación nacional & & & \\
\hline
\end{tabular}

Marcando cierto contraste con la situación anterior, otro tipo de procesos intermedios se afincan en altas capacidades de participación, manteniendo generalmente posiciones anti-tecnócratas. Se confía mucho en las bases pero se descuidan los aspectos de fortalecimiento del capital humano.

La construcción de tejido social es trabajada explícitamente y hay mucha dinámica social, lo que lleva también a procesos de planificación participativa. Este modelo empieza a fallar cuando se trata de hacer la gestión del plan y muchas veces se topa con bajas capacidades institucionales y ninguna articulación con procesos regionales y nacionales.

La dinámica social hace que se plantee, aunque sin mucha profundidad, el manejo de temas transversales y se busque asumir competencias sobre todo de tipo social, aunque no siempre hayan las capacidades para hacerlo.

\section{Procesos tradicionales:}

\begin{tabular}{lllll}
\hline & Área de evaluación & Bajo & Medio & Alto \\
\hline 1 & Construcción de tejido social & & \\
\hline 2 & Planificación local & & \\
\hline 3 & Gestión del plan & & \\
\hline 4 & Capacidad institucional & & \\
\hline 5 & Articulación nacional & & \\
\hline
\end{tabular}

El municipio tradicional, que tiene además una tendencia a perpetuarse y una ideología clientelar definida, tiende a hacer como eje de su acción la construcción de obras en la mayor cantidad posible y dirigida a todo tipo de clientelas. Suelen ser municipios con cierta capacidad de gestión, pero sin planificación. Tienen entre sus fortalezas la capacidad de acceder a recursos estatales y de agencias de desarrollo en función del resultado de las obras. Estos municipios descuidan la construcción del tejido social, la planificación y el fortalecimiento de la capacidad institucional. En su agenda no está el manejo de temas transversales y, menos aun, asumir nuevas competencias por la descentralización.

Muy fácilmente registran bajas calificaciones en lo referente a participación, no hay capacidad planificadora ni de gestión, hay bajo nivel en el personal municipal y, por supuesto, no hay la menor preocupación por articularse al sistema nacional, por manejar temas transversales o asumir nuevas competencias.

También en este rango, se pueden encontrar municipios sumidos donde hay condiciones de corrupción, con conflictos como forma cultural de enfrentar las situaciones locales. También se incluyen municipios y zonas $\sin$ experiencia de gobierno. 


\section{Bibliografía}

BURGWAL, Gerrit y CUELLAR, Juan Carlos. Planificación estratégica y operativa aplicada a gobiernos locales. SNV, Abya Yala. Quito. 1999.

CASTILLO, Hernán. Visión de la planificación y la participación comunitaria desde el nivel provincial (Presentación). CONCOPE. Quito. 2001.

DARQUEA, Gonzalo. Planeación estratégica municipal. IULA. Quito. 1998.

DARQUEA, Gonzalo. Criterios básicos para la participación ciudadana en el desarrollo local. FISDL. San Salvador. 2002.

GALLEGOS, Fernando. Proceso de Planificación Local Participativa.. PLP (presentación). AME. Quito. 2000.

ODEPLAN. La planificación en el Ecuador (presentación). ODEPLAN. Quito. 2000.

SÁENZ, Álvaro, et. al. Estándares para un Proceso de Desarrollo Local. ODEPLAN-AME-UNFPA- Quito. 2004.

SÁENZ, Álvaro. Herramientas para las Juntas Parroquiales Rurales. Diálogo 21. PNUD. Quito. 2000.

SÁENZ, Álvaro; et al. Herramientas para el mejoramiento del municipio. ICAM. Quito. 1993.

URRUTIA, Arturo y DARQUEA, Gonzalo. Criterios básicos. Procesos Participativos de Desarrollo Municipal. Manual de Aplicación. USAID. RTI. San Salvador. 2002.

\section{Anexo}

Ejemplo de matriz de aplicación 


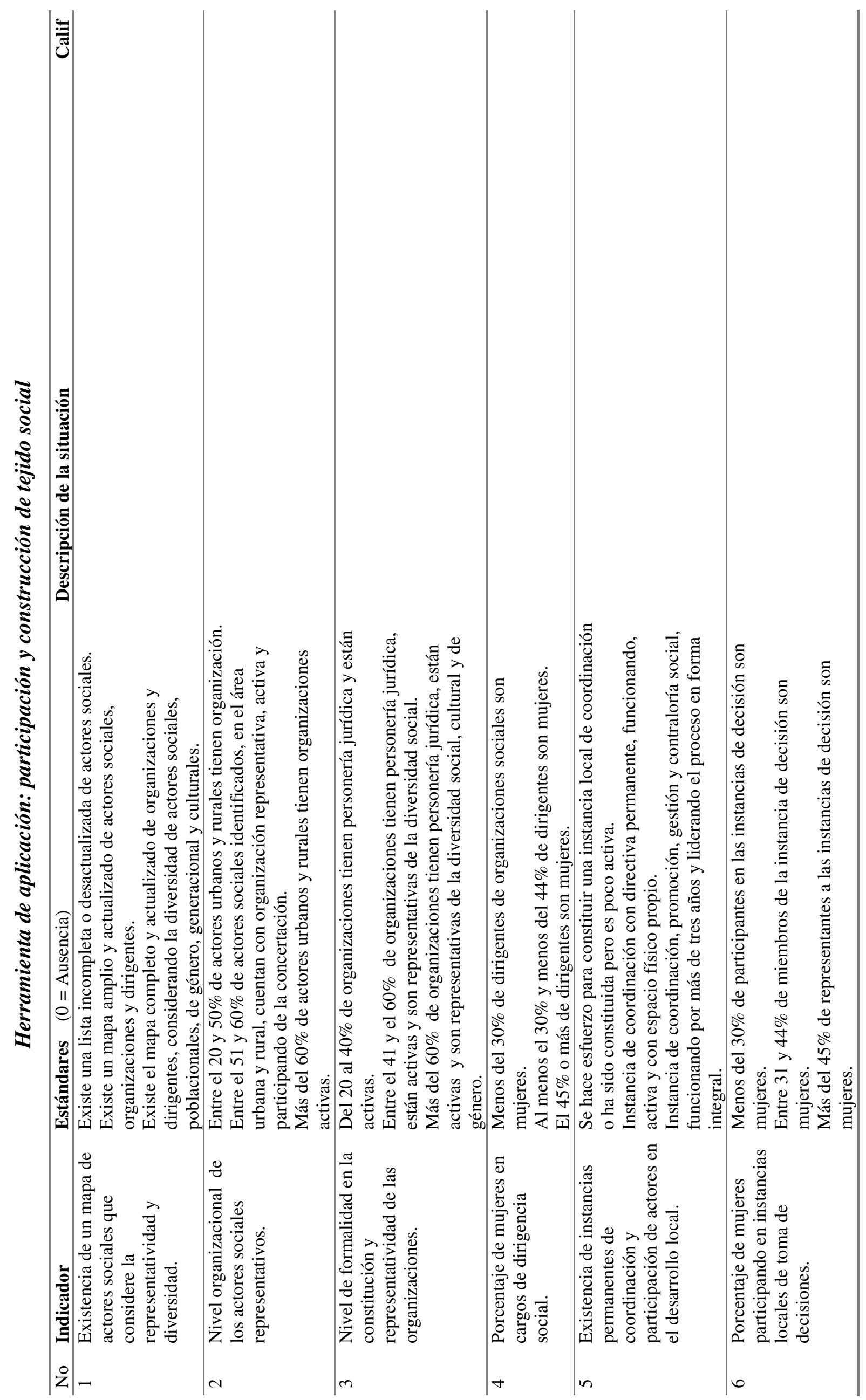




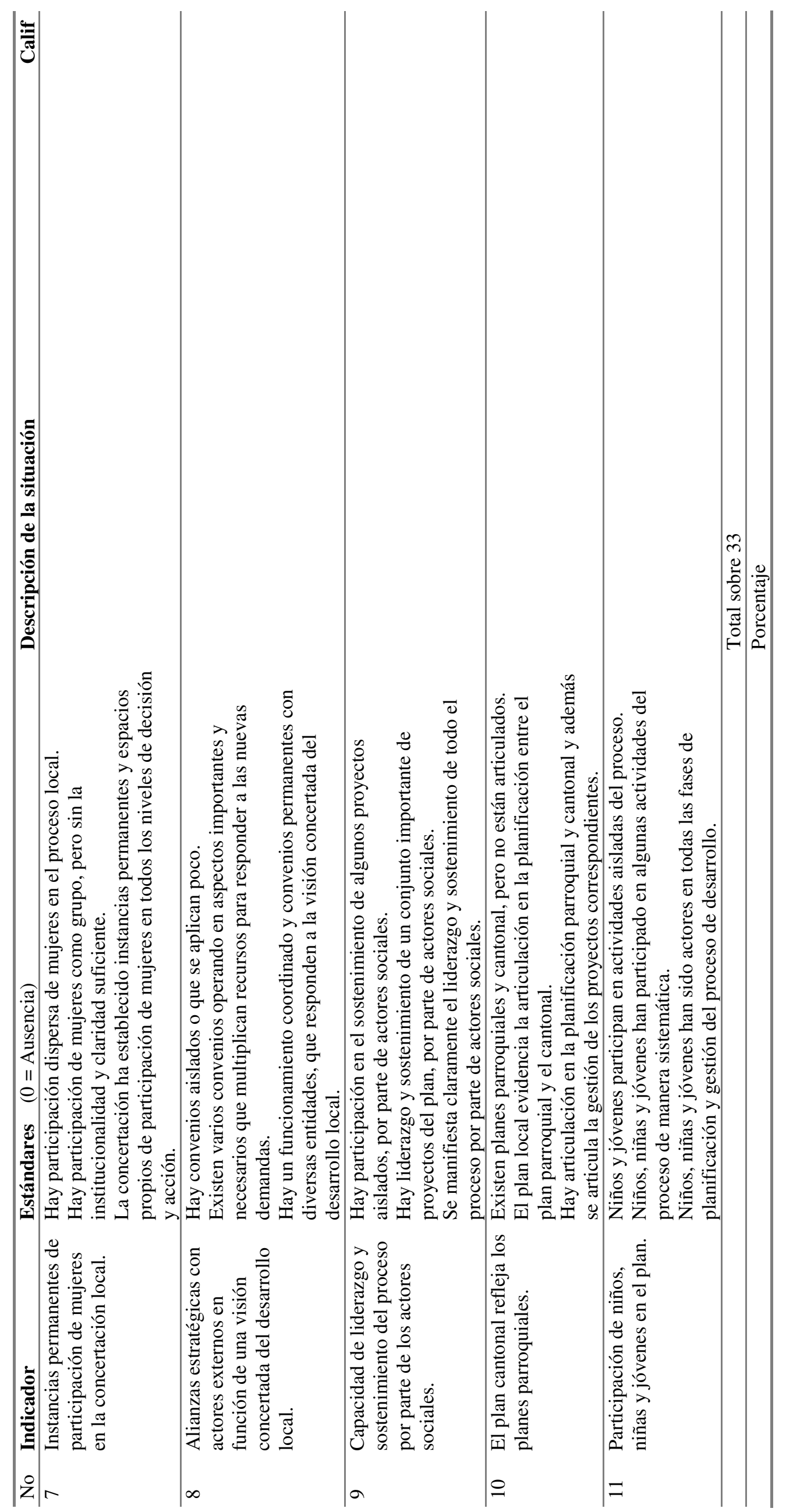

